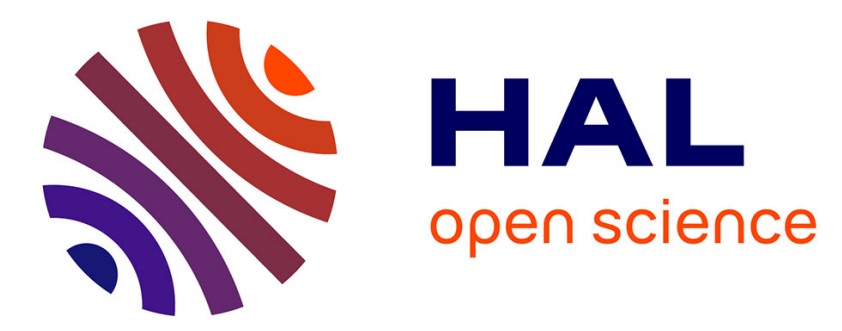

\title{
Prediction of harmonic sound power generated by a modern turbofan with heterogeneous OGV and internal bifurcations
}

\author{
V. Bonneau, C. Polacsek, R. Barrier, S. Lewy
}

\section{- To cite this version:}

V. Bonneau, C. Polacsek, R. Barrier, S. Lewy. Prediction of harmonic sound power generated by a modern turbofan with heterogeneous OGV and internal bifurcations. AIAA - AVIATION 2014 - 20th AIAA/CEAS Aeroacoustics Conference, Jun 2014, ATLANTA, United States. hal-01082931

\section{HAL Id: hal-01082931 \\ https://hal.science/hal-01082931}

Submitted on 14 Nov 2014

HAL is a multi-disciplinary open access archive for the deposit and dissemination of scientific research documents, whether they are published or not. The documents may come from teaching and research institutions in France or abroad, or from public or private research centers.
L'archive ouverte pluridisciplinaire HAL, est destinée au dépôt et à la diffusion de documents scientifiques de niveau recherche, publiés ou non, émanant des établissements d'enseignement et de recherche français ou étrangers, des laboratoires publics ou privés. 


\section{Prediction of harmonic sound power generated by a modern turbofan with heterogeneous OGV and internal bifurcations}

V. Bonneau, C. Polacsek, R. Barrier, S. Lewy

AVIATION 2014

20th AIAA/CEAS Aeroacoustics Conference

ATLANTA, U.S.A

16-20 juin 2014

\section{ONERA}

THE FRENCH AEROSPACE LAB 



\title{
Prediction of harmonic sound power generated by a modern turbofan with heterogeneous OGV and internal bifurcations.
}

\section{Prévision de la puissance sonore harmonique générée par une soufflante moderne avec stator hétérogène et bifurcations internes.}

\author{
par \\ V. Bonneau, C. Polacsek, R. Barrier, S. Lewy
}

\section{Résumé traduit :}

L'interaction des sillages générés par la soufflante avec les aubes du redresseur à la fréquence de passage des pales est la source principale du bruit de raies des turboréacteurs en régime d'approche. Les modèles de prévision du bruit d'interaction rotor-stator supposent des aubages axi-symétriques et des manches quasi-annulaires. Cependant, les stators des nouveaux moteurs (dits hétérogènes) sont caractérisés par des aubes non identiques et intègrent les bras supports et deux pylônes se prolongeant jusqu'à l'éjection. Ces effets technologiques mettent à défaut les outils de prévision existants actuellement utilisés par les motoristes en phase de conception. Pour cette raison, une méthode hybride fondée sur un calcul RANS 3D instationnaire en considérant la géométrie complète d'une maquette de moteur Snecma est proposée dans ce papier. Une dérivation de la formulation de Ffwocs-Williams et Hawkings (FWH) est mise en œuvre pour prendre en compte ces effets technologiques. L'impact de la rupture de symmétrie sur la distribution des modes angulaires (par comparaison avec le cas homogène idéal) ainsi que les effets des bifurcations internes sur la propagation acoustique aval sont étudies. Les prévisions de puissance sonore harmonique fournies par le chaînage RANS-FWH sont également comparés aux calculs directs, à partir d'extraction de champs de perturbations sur des sections de conduit prescrites en aval de l'OGV. Des premières comparaisons des résultats avec les mesures disponibles issues d'essais en banc moteur sur une maquette à échelle 1/2 sont discutées. 



\title{
Prediction of harmonic sound power generated by a modern turbofan with heterogeneous OGV and internal bifurcations
}

\author{
Virginie Bonneau * \\ Snecma Villaroche \\ Rond-point René Ravaud, 77550 Réau, France \\ Cyril Polacsek ${ }^{\dagger}$, Raphaël Barrier ${ }^{\ddagger}$, Serge Lewy $\S$ \\ Office National d'Etudes et de Recherches Aérospatiales - French Aerospace Lab
}

BP 72, 92322 Châtillon, France

\begin{abstract}
The interaction of wakes generated by the fan with the Outlet Guide Vanes (OGV) occurring at the blade passing frequency and its harmonics is mainly responsible for aeroengines tonal noise emission in approach conditions. Conventional rotor-stator interaction models assume axisymmetric rows and quasi-annular ducts. However, the stator of new engines is characterized by non-identical vanes (so-called heterogeneous OGV) and integrates two internal bifurcations up to the outlet. These new technologies invalidate the existing tools adopted by engine manufacturers at design stage.

For this reason, hybrid methodologies based on a 3D unsteady RANS simulation considering the complete geometry of a modern Snecma engine model are investigated in this paper. A derivation of Ffowcs Williams and Hawkings (FWH) integral formulation is proposed to take into account these technology effects. The impact of the heterogeneity on angular mode distribution (compared to an idealized homogeneous configuration) and the effect of internal bifurcations on downstream propagation are analyzed. The harmonic sound power predictions provided by RANS-FWH coupling are also compared to a direct assessment of the acoustic power obtained by extracting the perturbation fields over prescribed cross-sections behind the OGV. Finally, CFD data and acoustical predictions are compared to experimental data issued from a half-scaled turbofan test rig.
\end{abstract}

\section{Nomenclature}

$A_{m \mu}$ Mode amplitude relative to the mode $(m, \mu)$

$B \quad$ Rotor blade number

$c_{0} \quad$ Speed of sound

$f \quad$ Frequency

$G \quad$ Green's function

$I_{x} \quad$ Axial acoustic intensity

$k_{m \mu} \quad$ Axial wave-number relative to the mode $(m, \mu)$

$K \quad$ Total wave number

$l_{i} \quad$ Unsteady loads $(i=1,2,3)$

$m$ Azimuthal mode order

$M \quad$ Mach number

$\vec{n} \quad$ Local unit normal vector to the surface, with coordinates $\left(n_{x}, n_{r}, n_{\theta}\right)$

${ }^{*}$ PhD student, Snecma, Acoustic Division, virginie.bonneau@snecma.fr

${ }^{\dagger}$ Research engineer, ONERA, Computational Fluid Dynamics and Aeroacoustics Department (DSNA), cyril.polacsek@onera.fr

${ }_{\ddagger}$ Research engineer, ONERA, Applied Aerodynamics Department (DAAP), raphael.barrier@onera.fr

$\S$ Research engineer, ONERA, Computational Fluid Dynamics and Aeroacoustics Department (DSNA), serge.lewy@onera.fr 
$p \quad$ Pressure disturbance

$p_{m \mu} \quad$ Acoustic pressure relative to the mode $(m, \mu)$

$R_{\text {duct }}$ Duct radius

$S_{d u c t}$ Duct section

$S_{j_{V}} \quad$ Surface area relative to the $j_{V}$ th stator vane $\left(j_{V}=1, . ., 40\right)$

$u_{x} \quad$ Axial velocity disturbance

$V \quad$ Number of stator vanes

$\vec{X} \quad$ Source position, with coordinates $\left(x_{s}, r_{s}, \theta_{s}\right)$

$\vec{Y} \quad$ Observer position, with coordinates $(x, r, \theta)$

$\beta \quad \sqrt{1-M^{2}}$

$\rho_{0} \quad$ Fluid density

$\mu \quad$ Radial mode order

$\Psi_{m \mu}$ Radial eigenfunction relative to the mode $(m, \mu)$

\section{Introduction}

The interactions of wakes generated by the fan with the Outlet Guide Vanes (OGV) occurring at the blade passing frequency and its harmonics are the main source of aero-engines tonal noise emissions in approach conditions. Modern turbofans are characterized by new design including composite fan blades with low count and large chords, struts and pylons integrated to the OGV. Thus, the usual stator vane periodicity is lost, so that the interaction noise mechanism of the so-called heterogeneous OGV is fully tri-dimensional. These technological effects should be taken into account in the aeroacoustic evaluation of the engine, which is not possible using classical fast-running industrial tools. The objective of the present study is to propose an advanced computation method aiming at predicting the harmonic sound power due to interaction noise in such a realistic configuration.

It is achieved here by performing a 3D URANS calculation of the rotor-OGV stage (including struts and bifurcations), which requires to use a $360^{\circ}$ computation domain in the fixed stator frame. The CFD grid in the rotor frame can be restricted to one blade channel by using the phase-lagged approach. ${ }^{1}$ The acoustic field can be directly assessed from unsteady aerodynamics if the mesh density is fine enough, requiring quite heavy grid size and CPU time costs. An alternative issue is to try to use the FWH analogy generalized by Goldstein ${ }^{2}$ for ducted fan problems. Assuming that the tonal noise is essentially due to the interaction between the rotating fan wakes and the OGV row, sound sources are expected to be generated by the unsteady loads over all the rigid surfaces (vanes, struts and bifurcations) that can be provided by CFD too. The main difficulty is to relate the source to a downstream observer using an appropriate analytical Green's function in the presence of internal bifurcations. The problematic link to the acoustic propagation in a duct crossed by internal bifurcations has already been investigated by Bauers, ${ }^{3}$ suggesting a generalized formulation for the pressure distribution taking into account the thickness of the bifurcations. In this study both the heterogeneity of the stator and the presence of the bifurcations in the bypass duct are investigated. A few simplifications are suggested to solve this problem in order to predict the harmonic sound power in the bypass duct. A more direct approach for predicting the sound power based on the calculation and integration of the acoustic intensity over a prescribed cross-section downstream the OGV (using CFD disturbances) is also investigated.

Some preliminary results have already been presented in a short paper. ${ }^{4}$ In this more detailed communication, the focus is set on the filtering of the hydrodynamic modes from the CFD field which is mandatory when trying to use the well known Cantrell and Hart formulation for calculating the acoustic intensity. Moreover, further analyses are performed to validate the CFD data and the assumptions used for the acoustic predictions. By this way, the CFD vane pressure loads are compared to the measurements provided by pressure sensors mounted over stator vanes and the sound pressure level at outer wall is compared to wall-mounted microphones measurements. Finally, the sound power spectrum predictions downstream of the OGV is discussed related to the acoustic power estimations provided by an external microphone array. 


\section{Engine model configuration}

The engine studied is a half-scaled turbofan from Snecma. It is characterized by a new design including a fan constituted of 18 blades in composite with large chords strongly twisted. There are 40 OGV with two integrated pylons located at 6 and 12 o'clock axis and two integrated struts close to the 3 and 9 o'clock axis as shown in Fig. 1. Moreover, the OGV have different type of vanes with different stagger angles.

This model has undergone series of tests in the RACE aeroengine bench ${ }^{5}$ at Saclay in France. Figure 2 describes the available measurements in the RACE test rig used to validate the simulation and the acoustic tools. Pressure measurements with Kulite sensors mounted on the vane skins will be compared to harmonic pressure disturbances on the vane surfaces provided by CFD. Also, two wall-mounted microphones over a cross-section downstream of the OGV can serve to compare the sound pressure level calculated at the outer wall. These induct measurements are shown in Fig. 2(a). Moreover, measurements provided by an external microphone array (Fig. 2(b)) will allow to estimate the power level radiated downstream the turbofan. Assuming that the transmission coefficient is equal to 1 , these measurements can be compared to the sound power predictions performed in the bypass duct. This study is focused on the approach regime $(50 \%$ of the nominal regime).

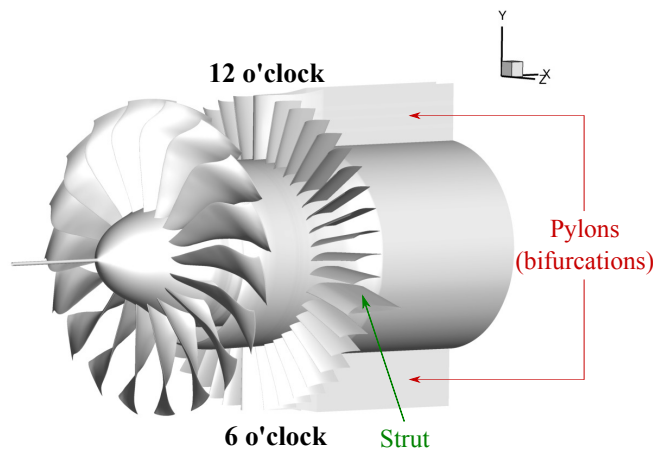

(a) 3D fan front view

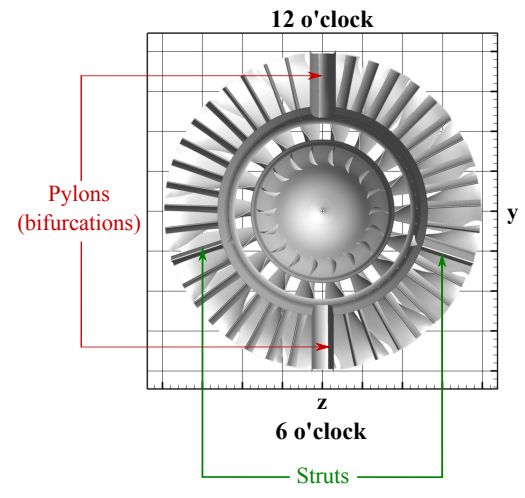

(b) $2 \mathrm{D}$ stator downstream view

Figure 1. Heterogeneous stator geometry with integrated struts and pylons.

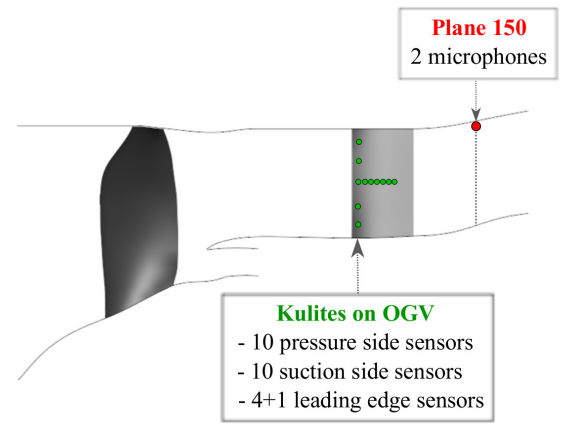

(a) Bypass duct

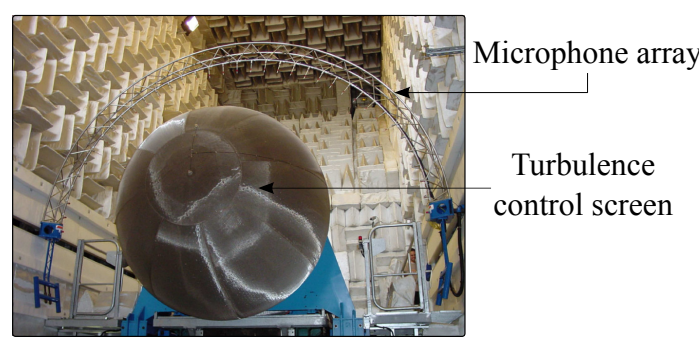

(b) External microphone array

Figure 2. Available measurements in the RACE test rig used in the paper

\section{URANS computations}

An Unsteady Reynolds-averaged Navier-Stokes (URANS) simulation is performed to assess the acoustic sources on the vanes and perturbation field in the bypass duct, related to wake interactions between the rotor ant the OGV. These data will be used as inputs for estimating the sound power calculation in the outlet at the blade passing frequency and its harmonics. 


\section{III.A. CFD solver and grid description}

Only one fan blade is modeled as it is homogeneous but the full $360^{\circ} \mathrm{OGV}$ geometry has to be meshed to take into account the effects of the stator heterogeneity and the presence of the pylons. Chorochronicity conditions are applied in the rotor stage.

The CFD solver used in this study is the ONERA's software elsA, ${ }^{6}$ which is based on a cell centered finite volume approach and a structured multi-block grid. The URANS computation is carried out with a k-l Smith turbulence model. The second order Jameson scheme is used for space discretization. The time discretization scheme is the implicit backward Euler method with a Gear under-iteration algorithm ensuring a second order accuracy. The time step is set to $1.710^{-6} \mathrm{~s}$ which leads to a CFL (Courant-Friedrich Levy) number lower than 1 excepted in the boundary layers. It corresponds to 400 time steps per blade passing period. Thus, a full rotor revolution requires 7200 iterations, and convergence is expected to be achieved beyond 45000 iterations (more than 6 revolutions have to be simulated).

The CFD grid (Fig. 3) is obtained with an O4H topology and designed to suit the acoustic requirements. A special attention is paid to the fan wakes convection and to the bypass duct propagation. Thus, the grid density is adjusted to capture vortices with at least 40 points per wavelength on the first two BPF, 30 points on $3 \mathrm{BPF}$, and at least 20 points for $4 \mathrm{BPF}$ and $5 \mathrm{BPF}$ (higher harmonics considered). The bypass duct domain is the most costly part of the grid due to the meshing of all OGV vanes, that is why the cells are highly stretched after the measurement cross-section (plane 150 downstream of the OGV in Fig. 2(a)) in order to limit the mesh size. Moreover a stretching zone has been added upstream of the fan in order to highly reduce the grid size while avoiding numerical reflexions. The whole grid totalises 66 million cells.

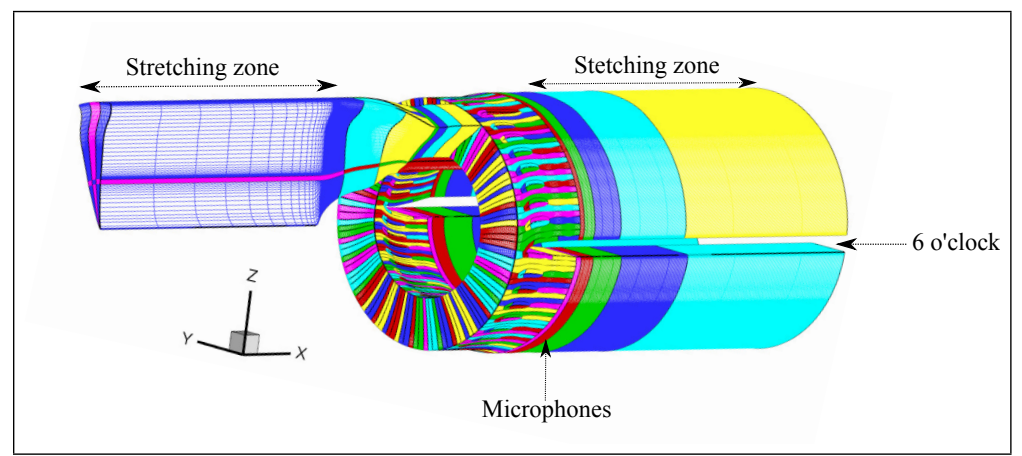

(a) Mesh of the fan-OGV duct

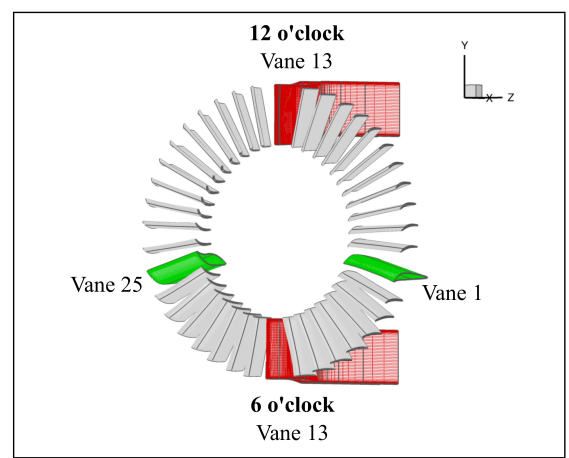

(b) OGV mesh skin

Figure 3. 3D multiblock mesh of the fan-OGV stage used for the URANS computation

\section{III.B. Basic flow analyses}

First of all, several RANS computations have been performed before launching the URANS simulation in order to reach the engine operating point conditions. The convergence of URANS calculation after 7 rotor revolutions has been checked on the stator stage by visualising disturbance fields and comparing RMS (Root Mean Square) levels related to the two last fan rotating periods.

Figure 4 displays the iso-entropy colour map, highlighting the interaction of the fan wakes with the stator vanes. It shows how the wakes generated by the OGV are spreading far into the bypass duct, up to the measurement cross-section. One can notice different shapes of wakes; in particular, the strut wake (Fig. 4 left) is deviated and is joining the wake of the neighboring vane. 


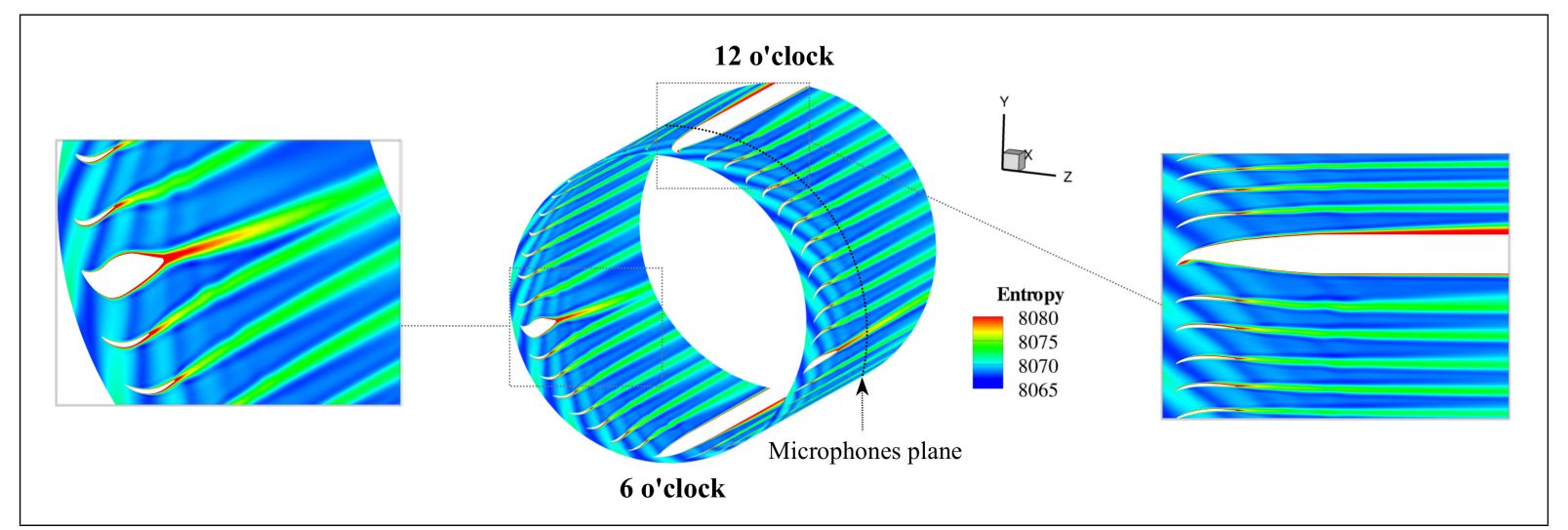

Figure 4. Entropy snapshot visualizing the rotor wakes interacting with the OGV and wakes generated by the stator vanes in the bypass duct (stator front view)

\section{III.C. Data extraction for acoustics}

In preparation for acoustical analysis, two kinds of extractions have been performed from the CFD data with a post-processing tool named Zeppelin. As previously mentioned in the introduction, two main approaches are investigated to predict the sound power at BPF tones.

The first method is based on an acoustic analogy. It requires to know the harmonic pressure disturbances over the stator vanes, plotted in Fig. 5. Figure 5(a) shows vane to vane differences and confirms that the most intense pressure harmonics corresponding to the dipolar sources are confined to the leading edge region.

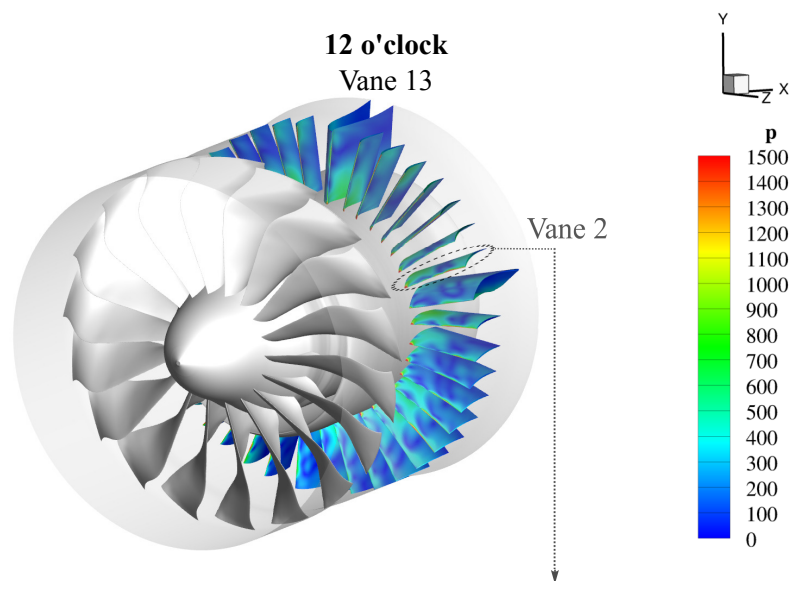

(a) Stator front view - $1 \mathrm{BPF}$

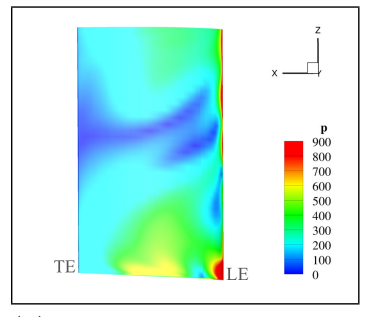

(b) Suction side of a standard vane - $1 \mathrm{BPF}$

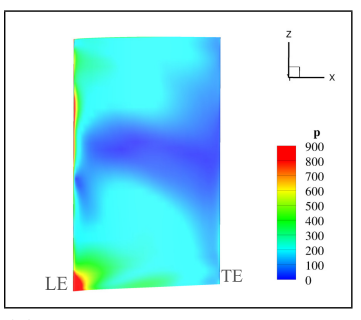

(c) Pressure side of a standard vane - $1 \mathrm{BPF}$

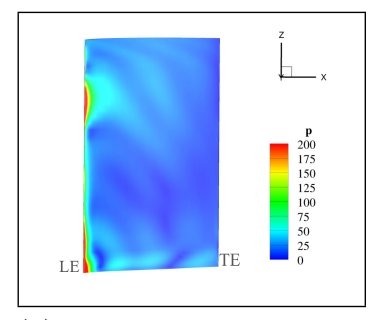

(d) Pressure side of a standard vane - $2 \mathrm{BPF}$

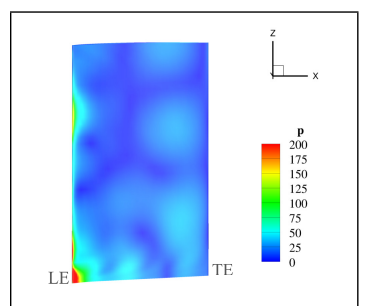

(e) Pressure side of a standard vane - $3 \mathrm{BPF}$

Figure 5. CFD data analyses on the OGV mesh skin used as input for the acoustic post-treatment based on the FWH analogy

The other approach is based on a direct calculation of sound intensity from the unsteady CFD field. The required inputs are the harmonics of pressure and axial velocity disturbances in the microphone crosssection displayed in Fig. 6. First of all, instantaneous pressure and axial velocity are extracted from the acoustical analysis plane (plane 150) and interpolated over a fixed ring with a radial and an angular uniform 
discetization. This ring (shown later in Fig. 20(b)), is meshed in order to well capture the acoustic modes using 101 points in the radial direction (maximum radial mode order equal to 5 on 3BPF), and 1001 points in angular direction (maximum spinning mode order equal to 31 on 3BPF). However, the plane 150 is crossed by the two internal bifurcations (Fig. 6), that is why the integrated values are set to zero if the nodes are located within the bifurcations.

The acoustic post-processing is presented in the next section.

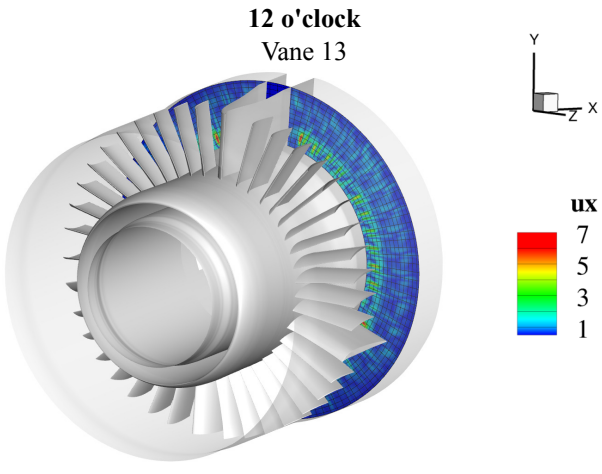

(a) Axial velocity field (1BPF) from plane 150 interpolated over the ring (print of 1 point on 8 )

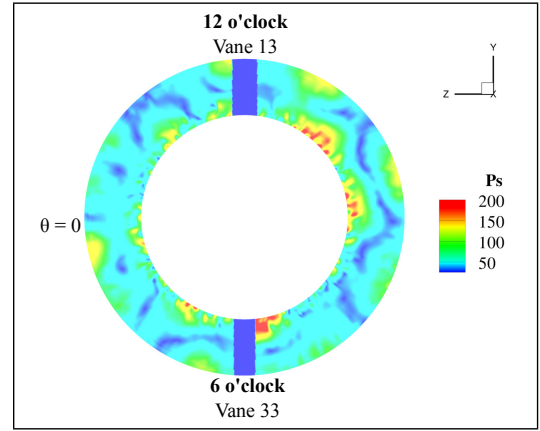

(b) Magnitude $(\mathrm{Pa})$ of pressure harmonic $1 \mathrm{BPF}$

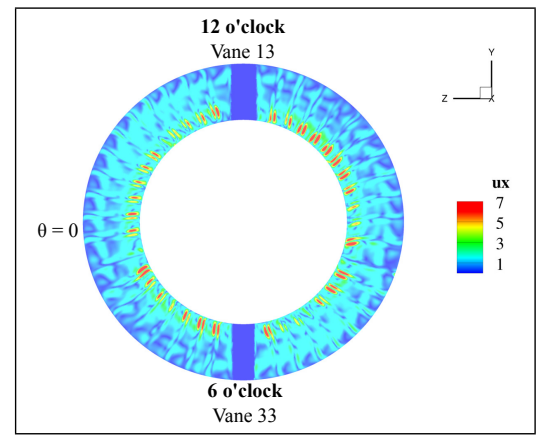

(e) Magnitude $(\mathrm{m} / \mathrm{s})$ of axial velocity har monic - $1 \mathrm{BPF}$

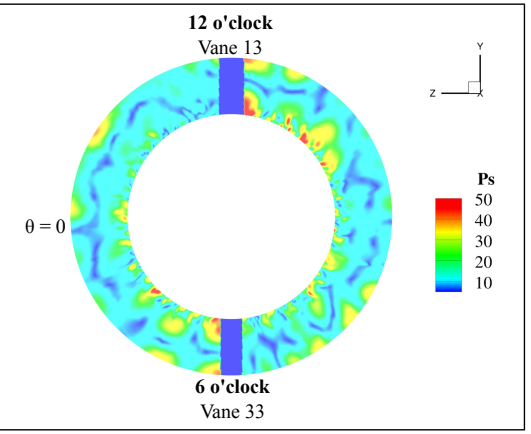

(c) Magnitude $(\mathrm{Pa})$ of pressure harmonic 2BPF

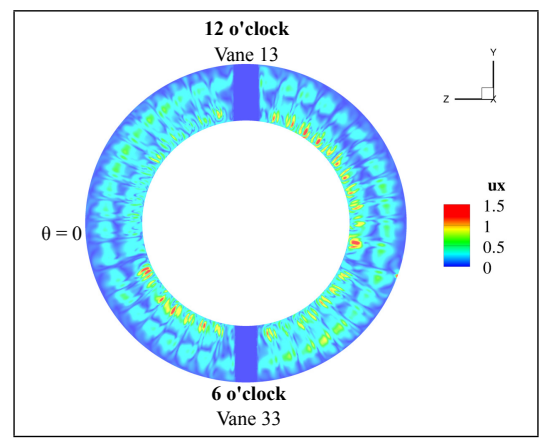

(f) Magnitude $(\mathrm{m} / \mathrm{s})$ of axial velocity harmonic - 2BPF

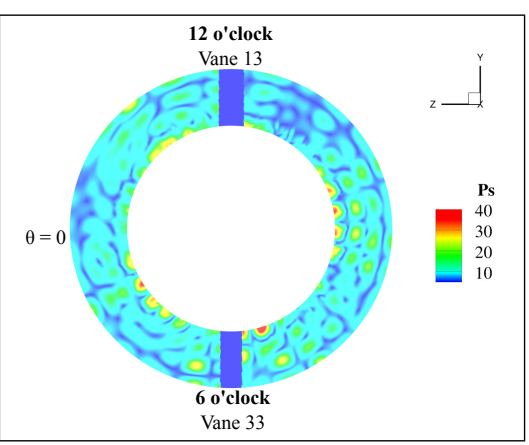

(d) Magnitude (Pa) of pressure harmonic $3 \mathrm{BPF}$

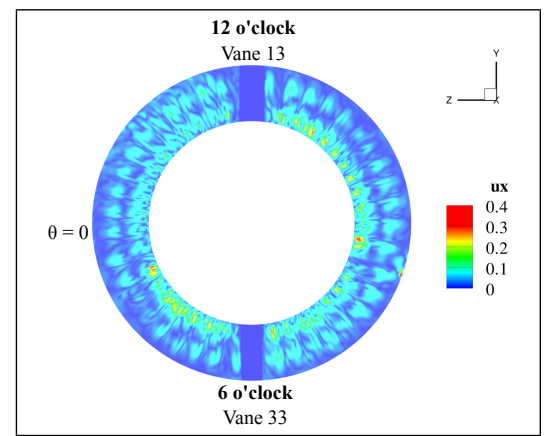

(g) Magnitude $(\mathrm{m} / \mathrm{s})$ of axial velocity harmonic - 3BPF

Figure 6. CFD data analyses in the microphone cross-section

\section{Acoustic models for predicting acoustic power generated by a modern fan integrating a heterogeneous stator and internal bifurcations}

Unsteady output data discussed in the previous section are used to compute the acoustic field in the bypass duct and more particularly the sound power at the blade passing frequency and its harmonics. The two approaches are investigated here, based either on an acoustic analogy or on a direct calculation of sound intensity from unsteady CFD field. 


\section{IV.A. FWH-based formulation for an heterogeneous stator}

The first approach is an extension of an integral formulation derived from the loading noise term of the FWH equation and using a Green's function valid for a semi-infinite annular duct with a uniform flow. This formulation was first proposed by Goldstein ${ }^{2}$ for rotor-stator interaction noise. It is extended here to heterogeneous OGV (see section II). The loading noise term of FWH formulation in the frequency domain writes:

$$
p(\vec{X}, f)=\int_{S_{d u c t}} l_{i}(\vec{Y}, f) \frac{\partial G(\vec{X}, f \mid \vec{Y})}{\partial y_{i}} d S
$$

where $G$ denotes the Green's function, $l_{i}$ the unsteady loads in the frequency domain, $\vec{Y}$ and $\vec{X}$ are respectively the source and observer coordinates.

In the homogeneous case, the interaction modes are given by the well-known Tyler and Sofrin $^{7}$ interaction mode formula $m=n B \pm k V$. In heterogeneous case the source integration has to be performed for each vane (instead of one in the homogeneous case). Thus, the symmetry break in the angular direction can be expressed by setting $V=1$ (single stator vane) in this formula, so that all cut-on propagating modes are considered. A first impact of having non-periodical vanes is that the BPF tone, usually cut-off for standard turbofans, is then cut-on. Neglecting the radial component of the loading and expanding over Fourier-Bessel modes, acoustic pressure relative to the mode $(m, \mu)$ without taking into account the internal bifurcations (fully annular duct) can be expressed as:

$$
p_{m \mu}(\vec{X}, f)=\sum_{j_{V}=1}^{V}\left[\int_{S_{j_{V}}} i\left(k_{m \mu} n_{x}+\frac{m}{r_{s}} n_{\theta}\right) \hat{p}_{n B}^{j_{V}}(\vec{Y}) G_{m \mu}^{j_{V}}(\vec{X}, f \mid \vec{Y}) d S\right] \quad \text { with } \quad m=n B \pm k
$$

In Eq. (2) $G_{m \mu}^{j_{V}}$ and $\hat{p}_{n B}^{j_{V}}$ denote respectively the modal Green's function and the Fourier component at frequency $f=n B N$ of the unsteady wall pressure on the $j_{V} t h$ vane.

Using cylindrical coordinates system $(x, r, \theta)$, the modal pressure solution is related to the mode amplitude, $A_{m \mu}$, and to the radial eigenfunctions, $\Psi_{m \mu}$, as:

$$
p_{m \mu}(x, r, \theta, f)=A_{m \mu}(f) \Psi_{m \mu}(r) \mathrm{e}^{-i\left(m \theta+k_{m \mu} x\right)}
$$

The in-duct sound power then can be obtained from usual expression:

$$
W_{F W H}(f)=\sum_{m, \mu} \frac{\pi R_{d u c t}^{2}}{\rho_{0} c_{0}} \frac{K\left(\beta^{2} k_{m \mu}+M K\right)}{\left(K-M k_{m \mu}\right)^{2}}\left|A_{m \mu}(f)\right|^{2}
$$

We are going to show in the following sub-section that, under a few simplifications, Eq. (4) should be still valid in the presence of internal bifurcations.

\section{IV.B. Sound power calculation including internal bifurcations}

A specificity of nowadays aeroengines is the presence of internal bifurcations for which acoustic propagation in the duct can be modeled using geometrical simplification as proposed for example by Druon ${ }^{8}$ and also used in [9]. It consists in replacing the 6 o'clock and 12 o'clock pylons by two flat plates giving rise to a C-shaped duct sketched in Fig. 7.

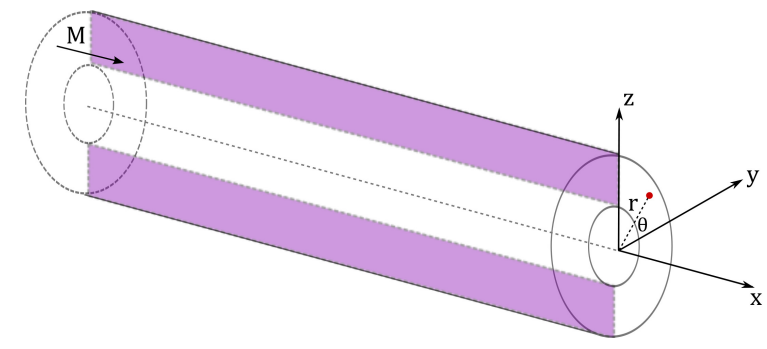

Figure 7. C-shaped annular duct with flat plate bifurcations (from [9]) 
By this way, the C-duct modal pressure field is defined by identical radial eigenfunctions and axial wavenumbers, but characterized by standing waves in the angular direction (for $m \neq 0$ ), which can be expressed for $\theta \in]-\frac{\pi}{2}, \frac{\pi}{2}[\cup] \frac{\pi}{2}, \frac{3 \pi}{2}[$ as:

$$
\left\{\begin{array}{lll}
p_{m \mu}^{C}(x, r, \theta, f)=P_{m \mu}^{C}(f) \Psi_{m \mu}(r) 2 \cos \left[m\left(\theta \pm \frac{\pi}{2}\right)\right] \mathrm{e}^{-i k_{m \mu} x} & \text { if } & m \neq 0 \\
p_{0 \mu}^{C}=p_{0 \mu} & \text { if } & m=0
\end{array}\right.
$$

The modal pressure field relative to the plane mode is the same with or without the bifurcations. Equation (5) has to be compared to the pressure distribution established by Sijtsma in [3] for C-shaped ducts with constant apex angle $\theta_{0}$ over the radius. Sijtsma proposed to introduce a non-integer azimuthal mode, defined by $\tilde{m}=m \pi / \theta_{0}$, in the pressure distribution formulation in order to take into account the thickness of the bifurcations. When $\theta_{0}$ tend to $\pi$ (flat plate assumption) the azimuthal mode is an integer and the pressure distribution established in [3] verify Eq. (5), which is comforting about the reliability of the formulation of the flat plate assumption used in this paper.

It can be also established that the C-duct modal Green's function, $G_{m \mu}^{C}$, can be derived from the fully annular duct solution and written as:

$$
\begin{cases}G_{m \mu}^{C}\left(x, r, \theta \mid x_{s}, r_{s}, \theta_{s}\right)=G\left(x, r \mid x_{s}, r_{s}\right) 2 \cos \left[m\left(\theta_{s} \pm \frac{\pi}{2}\right)\right] \cos \left[m\left(\theta \pm \frac{\pi}{2}\right)\right] & \text { if } \quad m \neq 0 \\ G_{0 \mu}^{C}=G_{0 \mu} & \text { if } \quad m=0\end{cases}
$$

Introducing Eq. (6) in Eq. (2) and after simple mathematical developments, it is straightforward to show that:

$$
\int_{0}^{2 \pi}\left|p_{m \mu}^{C}(x, r, \theta, f)\right|^{2} d \theta=\int_{0}^{2 \pi}\left|p_{m \mu}(x, r, \theta, f)\right|^{2} d \theta
$$

Hence, from Eq. (7) it is established that the harmonic sound power in the C-duct, $W_{F W H}^{C}$, remains unchanged (with respect to an annular duct without bifurcations):

$$
W_{F W H}^{C}(f)=W_{F W H}(f)
$$

The following estimations provided by the FWH formulation for a heterogeneous stator with internal bifurcations in Section V are founded on this flat plate assumption.

\section{IV.C. Cantrell \& Hart formulation}

In order to check the reliability of this flat plate approximation, the sound power calculation provided by Eq. (3) is compared to two other estimations using the URANS output data over a prescribed cross-section downstream of the stator vanes as discussed in Section III.C.

The first method, actually the most rigorous, is based on the direct calculation of the acoustic intensity using Cantrell and Hart $(\mathrm{C} \& \mathrm{H})$ expression ${ }^{10}$ valid for irrotational flows. The normal component of the acoustic intensity in a cross-section perpendicular to the duct axis is the axial component, $I_{x}$, given by:

$$
I_{x}(\vec{X}, f)=\frac{1}{2} \Re\left[\left(1+M_{x}(\vec{X})^{2}\right) p(\vec{X}, f) u_{x}^{*}(\vec{X}, f)+M_{x}\left(\rho_{0} c_{0}\left|u_{x}(\vec{X}, f)\right|^{2}+\frac{|p(\vec{X}, f)|^{2}}{\rho_{0} c_{0}}\right)\right]
$$

$\Re$ is the real part, $p$ and $u_{x}$ are respectively the harmonic pressure disturbances and the harmonic axial velocity disturbances extracted from the CFD simulation over the cross-section, as illustrated in Fig. 6. The sound power spectrum, $W_{C H}$, is obtained by integrating the axial intensity over the cross-section, $S_{d u c t}$, chosen perpendicular to the axis:

$$
W_{C H}(x, f)=\int_{S_{d u c t}} I_{x}(x, r, \theta, f) d S
$$

Such approach has been successfully applied to several turbofan model configurations, ${ }^{12}$ when focusing on inlet propagation (upstream of the fan). In the present case, the integration surface is an annular section in 
the bypass duct and the interpolated data are set to zero if the nodes are located within the bifurcations. The downstream case is more complicated than the inlet case due to the presence of wakes as it will be discussed later.

\section{IV.D. Modal expansion formulation}

The second verification is based on a modal expansion of CFD data using the modal form given by Eq. (5). The modal expansion is quite similar to the Fourier-Bessel transformation used for example in [12], but in which the angular-Fourier transform is replaced by a projection over a real cosine function in order to model the standing waves due to the presence of the bifurcations (flat plate assumption). It writes:

$$
\left\{\begin{array}{llll}
p_{m}^{1}(x, r, f)=\frac{1}{\pi} \int_{\frac{\pi}{2}}^{\frac{3 \pi}{2}} p(x, r, \theta, f) \cos \left[m\left(\theta-\frac{\pi}{2}\right)\right] d \theta & \text { if } \quad m \neq 0 \quad \text { and } \theta \in] \frac{\pi}{2}, \frac{3 \pi}{2}[ \\
p_{m}^{2}(x, r, f)=\frac{1}{\pi} \int_{-\frac{\pi}{2}}^{\frac{\pi}{2}} p(x, r, \theta, f) \cos \left[m\left(\theta+\frac{\pi}{2}\right)\right] d \theta & \text { if } \quad m \neq 0 \quad \text { and } \theta \in]-\frac{\pi}{2}, \frac{\pi}{2}[ \\
p_{0}(x, r, f)=\frac{1}{2 \pi} \int_{0}^{2 \pi} p(x, r, \theta, f) d \theta & \text { if } \quad m=0 &
\end{array}\right.
$$

Then the field is projected over the Bessel functions $\Psi_{m \mu}(r)$ (keeping the same basis for the radial functions), associated to each acoustic mode $(m, \mu)$, as given by Eq. (5), in order to assess the mode amplitude, $P_{m \mu}^{C}$ :

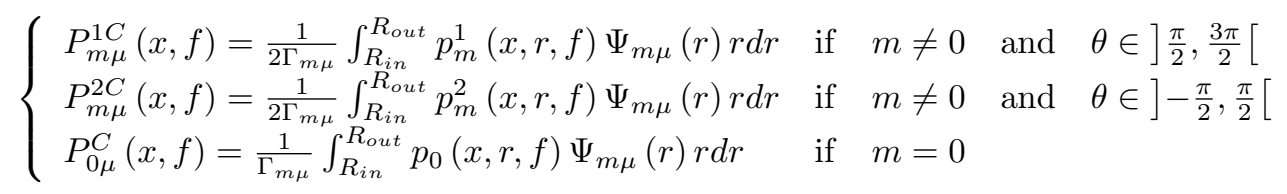

where $R_{\text {in }}$ and $R_{\text {out }}$ are respectively the inner and the outer radius of the duct, and the classical normalization function, $\Gamma_{m \mu}$ defined by: $\Gamma_{m \mu}=\int_{R_{\text {in }}}^{R_{\text {out }}} \Psi_{m \mu}^{2}(r) r d r$.

Finally, the sound power spectrum can be estimated using the same expression as Eq. (4):

$W_{\text {expand }}(x, f)=\sum_{m, \mu} \frac{\pi R^{2}}{\rho_{0} c_{0}} \frac{K\left(\beta^{2} k_{m \mu}+M K\right)}{\left(K-M k_{m \mu}\right)^{2}}\left|P_{m \mu}^{C}(x, f)\right|^{2} \quad$ with $\quad P_{m \mu}^{C}(x, f)=\frac{1}{2}\left(P_{m \mu}^{1 C}+P_{m \mu}^{2 C}\right) \quad$ if $\quad m \neq 0$

\section{Direct CFD and FWH-based predictions}

\section{V.A. FWH-based predictions: analyses of the stator heterogeneity effect}

First of all the convergence of URANS calculation has been checked by comparing RMS pressure disturbances on the OGV surface issued from two consecutive blade passing periods. About 7 rotor revolutions are required to get a fully converged solution for which the RMS fields have been found to be identical.

The available FWH code has been extended to take into account the heterogeneous stator (formulation given by Eq. (2)). Moreover, we have shown in Sub-section IV.B that when replacing the 6 o'clock and 12 o'clock pylons by two flat plates the harmonic sound power level with two internal bifurcations was expected to be the same as without bifurcation. The estimations provided by the FWH formulation and given by Eq. (2) for a heterogeneous stator with internal bifurcations are based on this assumption.

Overall sound power level (OAPWL) of homogeneous-like stator predictions obtained by duplicating each respective vane (with related CFD data) in the azimuthal direction and applying a suited phase shift is compared to the heterogeneous case in Fig. 8(a). The heterogeneous stator is clearly noisier than any homogeneous stator configuration, due to the dominant contribution of the 1BPF (cut-off for homogeneous cases). Indeed, by removing the $1 \mathrm{BPF}$ contribution, the level drops by $10 \mathrm{~dB}$ (green bar compared to red bar). As expected in homogeneous-like configurations, the noisiest vanes are the internal bifurcations (vane 13 and vane 33), certainly due to their quite large airfoil thickness leading to a larger surface in the leading edge region.

The previous results are supplemented by the sound power spectrum on the first three tones (1BPF to 3BPF in Fig. 8(b)) for typical homogeneous cases. The fundamental is cut-off in homogeneous configurations (in accordance to the Tyler and Sofrin theory) whereas this tone is dominating in the heterogeneous case. 


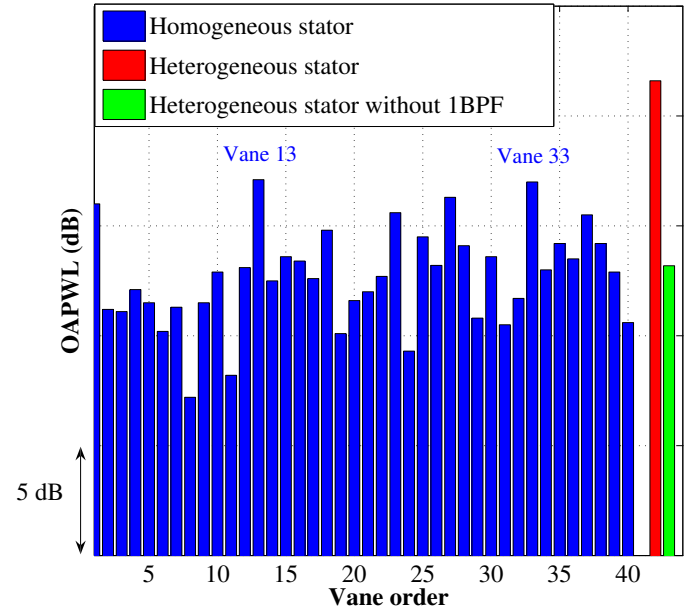

(a) OAPWL calculated for homogeneous-like stators (blue), heterogeneous stator (red), and for heterogeneous stator removing the $1 \mathrm{BPF}$ contribution (green)

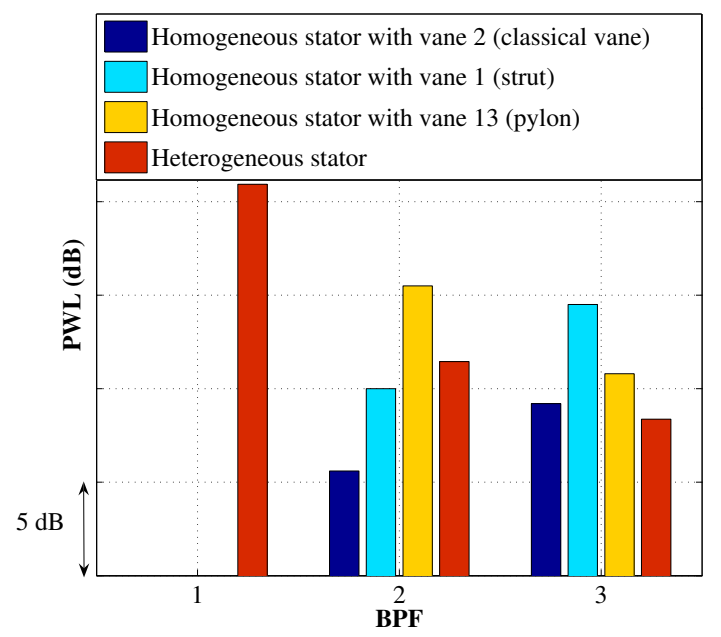

(b) PWL (dB) spectra predicted for heterogeneous stator (red) and for three configurations of homogeneous-like stator

Figure 8. FWH-based sound power predictions for homogeneous and heterogenous stators downstream the OGV

\section{V.B. Direct CFD predictions according to the Cantrell \& Hart formulation and the modal expansion approach}

To validate the modal expansion formulation, the real part of harmonic pressure issued from the CFD computation (plotted in Fig. 9 on top) is compared to the real part of harmonic pressure obtained after modal reconstruction (plotted in Fig. 9 on bottom). The reconstructed pressure field is obtained as:

$$
\left\{\begin{array}{lll}
p^{1}(x, r, \theta, f)=\sum_{m, \mu} P_{m \mu}^{1 C}(x, f) \Psi_{m \mu}(r) 2 \cos \left[m\left(\theta-\frac{\pi}{2}\right)\right] \mathrm{e}^{-i k_{m \mu} x} & \text { if } \quad m \neq 0 \text { and } \theta \in] \frac{\pi}{2}, \frac{3 \pi}{2}[ \\
p^{2}(x, r, \theta, f)=\sum_{m, \mu} P_{m \mu}^{2 C}(x, f) \Psi_{m \mu}(r) 2 \cos \left[m\left(\theta+\frac{\pi}{2}\right)\right] \mathrm{e}^{-i k_{m \mu} x} & \text { if } m \neq 0 \text { and } \theta \in]-\frac{\pi}{2}, \frac{\pi}{2}[ \\
p(x, r, \theta, f)=\sum_{\mu} P_{0 \mu}^{C} \Psi_{0 \mu}(r) \mathrm{e}^{-i k_{0 \mu} x} & \text { if } & m=0
\end{array}\right.
$$

The shapes of angular patterns (characterized by an alternation of nodes and antinodes) are very similar between the reconstructed and raw CFD pressure fields, especially at 1BPF. The results are a bit less accurate when increasing the frequency, probably due to 3D scattering effects occurring when the acoustic wave length is not large enough anymore compared to the thickness of the bifurcation. Thus, these results tend to show that the modal expansion using the flat plate assumption is quite reliable.

Figure. 10 shows a comparison of the power level spectrum predicted by the three methods previously discussed using Eqs. (4), (10) and (13). The C\&H solution (in green) highly over-estimates the PWL at 1BPF and 2BPF compared to the FWH solution (in blue), whereas the modal approach (in red) provides a much better agreement. This gap might be attributed to the presence of hydrodynamic modes generated by flow separation mainly in the stator hub region, and responsible for velocity disturbances triggered by the rotor blade wake passages. This is clearly visible in Fig. 6, showing the magnitude of axial velocity disturbance harmonics (on bottom) over the cross-section, and revealing spots at the vane locations (excepted for the two bifurcations). These prints are not linked to acoustic modes for two obvious reasons: velocity levels are 10 times higher than the expected acoustic velocity magnitude order $\left(p / \rho_{0} c_{0}\right)$, and angular mode order $(m=20)$ should be cut-off on $1 \mathrm{BPF}$ and $2 \mathrm{BPF}$. These velocity fluctuations have to be related to the stator wakes spreading far away beyond the OGV as indicated in Fig. 4. On the other hand, the plots related to pressure disturbance field (Fig. 6, top) do not highlight any similar spots but rather show expected cancellation patterns in accordance to the standing waves. This might explain the reason why the modal expansion approach only using pressure inputs (see Eq. (13)) is not sensitive to the presence of these hydrodynamic modes and seems to provide more reliable estimations (particularly for 1BPF and 2BPF). 


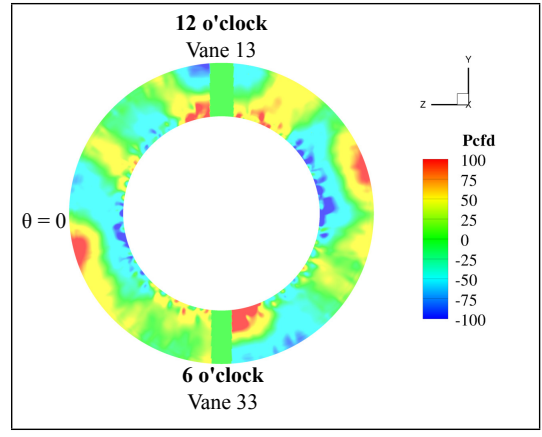

(a) Raw CFD - 1BPF

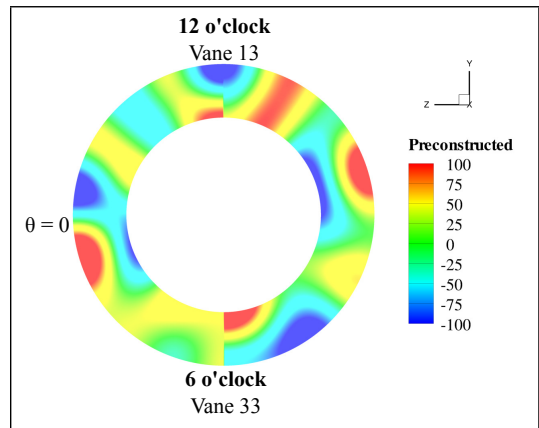

(d) Modal reconstruction - $1 \mathrm{BPF}$

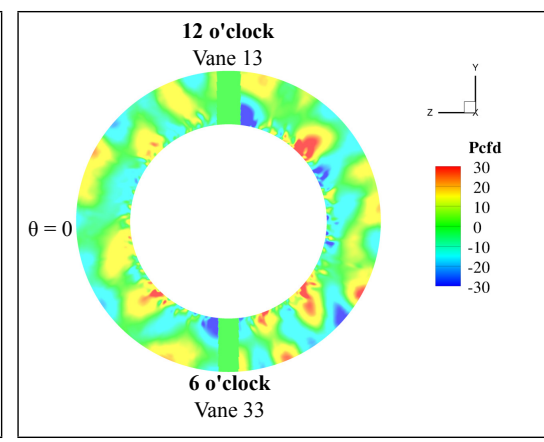

(b) Raw CFD - 2BPF

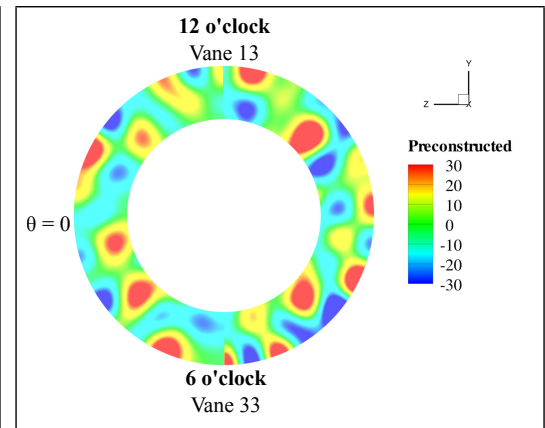

(e) Modal reconstruction - $2 \mathrm{BPF}$

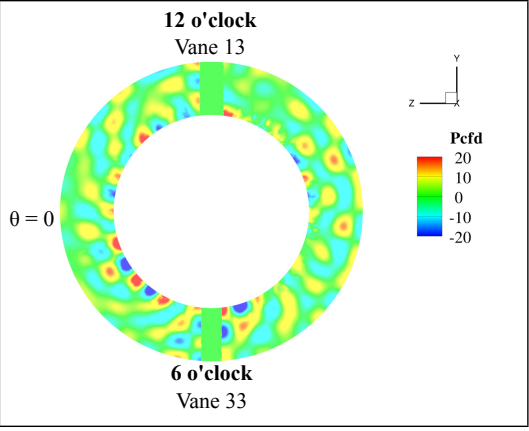

(c) Raw CFD - 3BPF

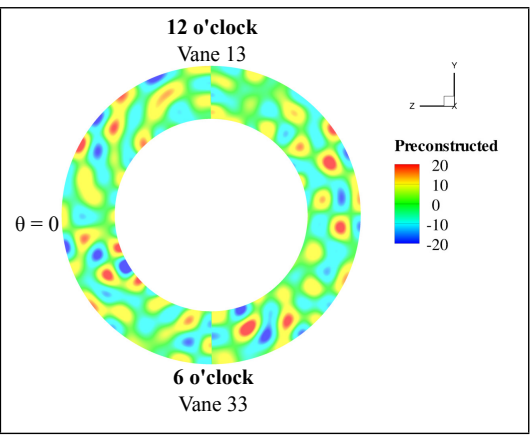

(f) Modal reconstruction - 3BPF

Figure 9. Analysis of the validity of the modal expansion - Real part (Pa) of harmonic pressure in the microphone cross-section issued from raw CFD Fourier transform (top) and from modal reconstruction (bottom)

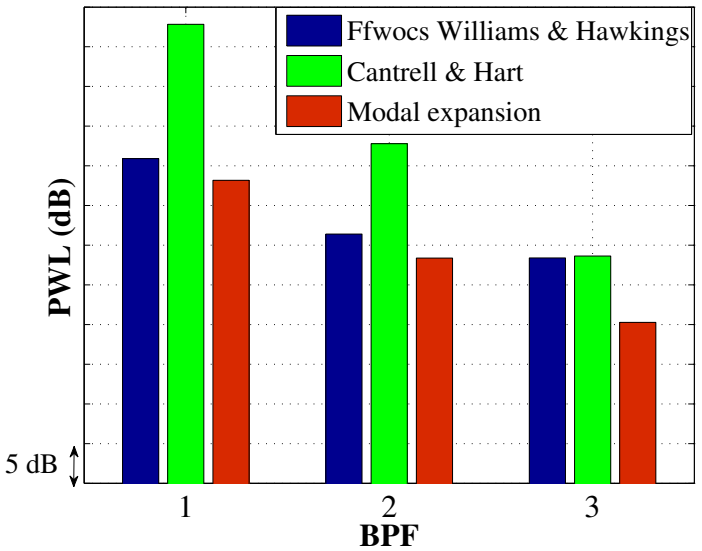

Figure 10. PWL (dB) spectra predicted from FWH (blue) and both direct calculation methods: C\&H (green) and modal expansion (red)

These explanations are confirmed by the modal content of the pressure and the axial velocity fields analyzed in Fig. 11 that plots the magnitude of the angular-Fourier transform (in the microphone section) against the radius for each tones. The black vertical lines mark the theoretical limits of the propagating modes. The modal content for the pressure field (left) clearly highlights the cut-off effects, which confirms the reliability of CFD data and the modal approach of the sound field in the bypass duct. On the contrary, the modal content for the axial velocity field (right) does not exhibit the cut-off, probably due to the presence of hydrodynamic modes. 


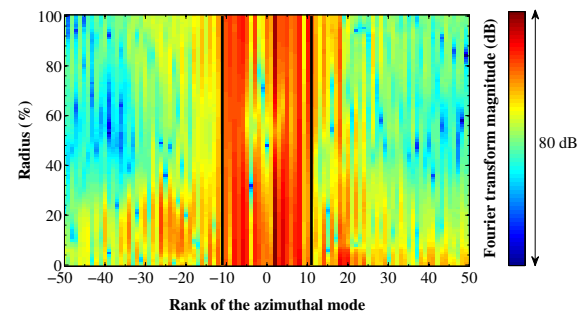

(a) Modal content of the pressure field (dB) $1 \mathrm{BPF}$

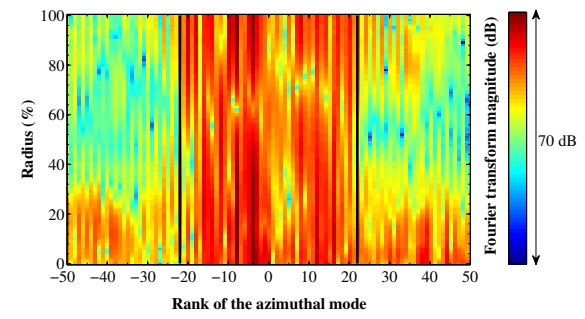

(c) Modal content of the pressure field (dB) $2 \mathrm{BPF}$

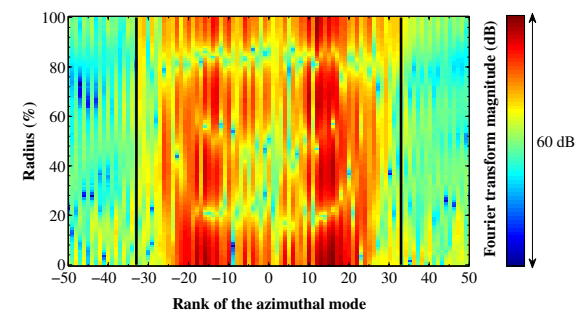

(e) Modal content of the pressure field (dB) $3 \mathrm{BPF}$

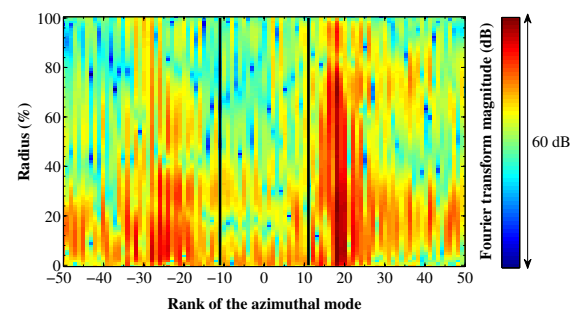

(b) Modal content of the axial velocity field (dB) $-1 \mathrm{BPF}$

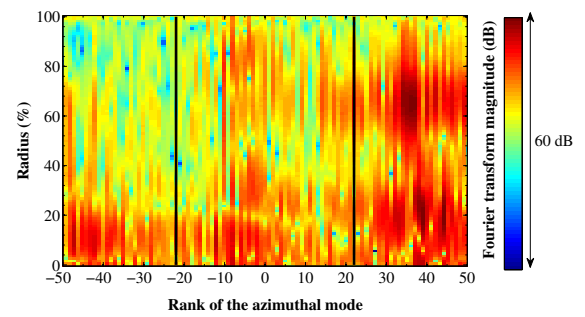

(d) Modal content of the axial velocity field (dB) $-2 \mathrm{BPF}$

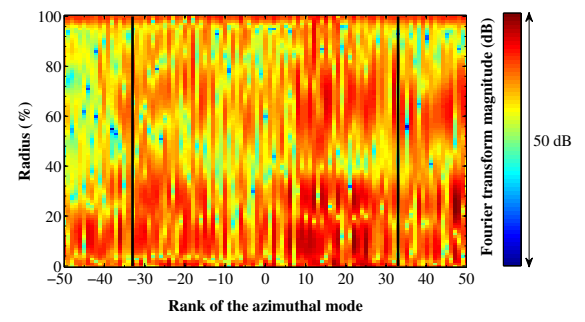

(f) Modal content of the axial velocity field (dB) $-3 \mathrm{BPF}$

Figure 11. 2D angular-Fourier transform of CFD pertubation fields (pressure on left, axial velocity on right) for the three first tones

Hence, hydrodynamic modes need to be filtered from the velocity field to improve the acoustic power estimations using the $\mathrm{C} \& \mathrm{H}$ formulation.

\section{V.C. Hydrodynamic modes filtering}

A simple way proposed here for extracting the hydrodynamic contribution from the CFD disturbances is based on the differences of the phase velocity between vortical and acoustic waves. The hydrodynamic perturbations are propagating at the convection velocity (expected to be nearly equal to the axial mean velocity, i.e. around $120 \mathrm{~m} / \mathrm{s}$ ), whereas the acoustic perturbations are propagating at the sound velocity added to the flow convection (i.e. around $460 \mathrm{~m} / \mathrm{s}$ ).

First of all, the convection velocity has to be estimated in the bypass duct. It is achieved by calculating the cross-spectrum of CFD disturbance fields (pressure and axial velocity) between several cross-sections downstream of the OGV. The cross-spectrum related to the axial velocity between the sections at axial positions $x_{1}$ and $x_{2}, S_{u_{x_{1}} u_{x_{2}}}$, is expressed as:

$$
S_{u_{x_{1}} u_{x_{2}}}\left(x_{1} \mid x_{2}, f\right)=u_{x}\left(x_{1}, f\right) u_{x}^{*}\left(x_{2}, f\right)
$$

Then the convection wave number, $K_{c}$, is deduced from the cross-spectrum phase, $\phi$, by:

$$
K_{c}=\frac{\phi}{\left(x_{2}-x_{1}\right)}
$$

The convection velocity, $U_{c}$, is directly deduced from the convection wave number thanks to the conventional Taylor assumption (frozen flow):

$$
U_{c}=\frac{2 \pi f}{K_{c}}
$$


2D iso-contour maps of estimated convection velocities are plotted in Fig. 12. The magnitude of the convection velocity associated to the axial velocity field plotted in Fig. 12(b) is similar to the magnitude of the mean axial velocity plotted in Fig. 12(a): the maximum velocity $(140 \mathrm{~m} / \mathrm{s})$ is located between the vane wakes, whereas the minimum velocity is located on the outer wall $(80 \mathrm{~m} / \mathrm{s})$ and the mean value is around $110 \mathrm{~m} / \mathrm{s}$. The convection velocity associated to the pressure disturbances plotted in Fig. 12(c) is greater than $400 \mathrm{~m} / \mathrm{s}$ almost everywhere because the pressure field is largely dominated by acoustic modes.

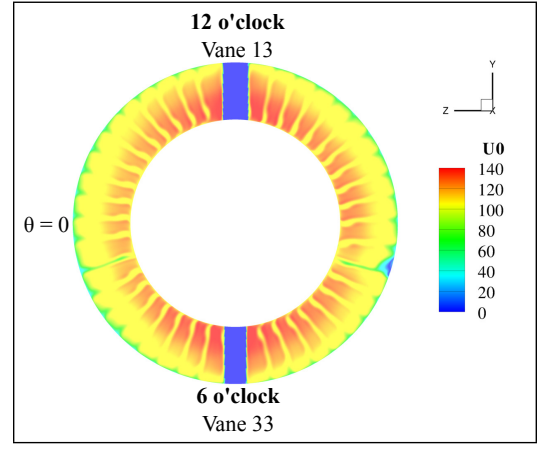

(a) Magnitude $(\mathrm{m} / \mathrm{s})$ of the mean axial velocity

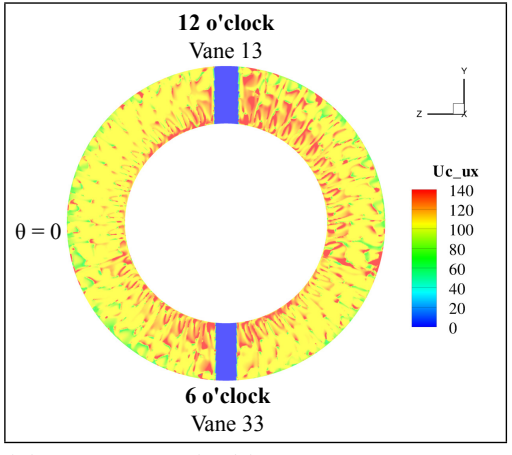

(b) Magnitude $(\mathrm{m} / \mathrm{s})$ of the convection velocity related to the axial velocity $(1 \mathrm{BPF})$

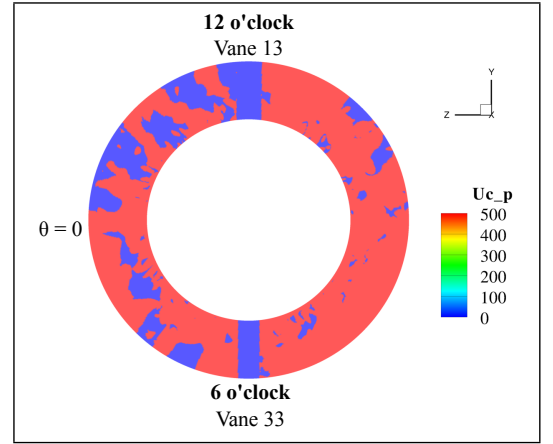

(c) Magnitude $(\mathrm{m} / \mathrm{s})$ of the convection velocity related to the pressure $(1 \mathrm{BPF})$

Figure 12. Analysis of the mean axial velocity field and of the convection velocity fields in the microphones section (stator downstream view)

Then the hydrodynamic component of the axial velocity field, $u_{x_{\text {hydro }}}$, can be calculated at the axial position $x_{0}$ by performing a spatial Fourier transform over the convection wave number:

$$
u_{x_{\text {hydro }}}\left(x_{0}, f\right)=\frac{K_{c}}{2 \pi} \int_{x_{0}-\frac{\pi}{K_{c}}}^{x_{0}+\frac{\pi}{K_{c}}} u_{x}(x, f) \mathrm{e}^{i K_{c} x} d x
$$

The distance between the first and the last extraction plane has to be longer than the convection wave length in the axial direction (about $7 \mathrm{~cm}$ at $1 \mathrm{BPF}$ ) in order to capture a full spatial period when calculating the hydrodynamic contribution (a Hanning window is used to limit the truncation effects).

Finally, the hydrodynamic part filtering in order to get the purely acoustic wave is obtained by applying Eq. (19):

$$
u_{x_{f i l t}}\left(x_{0}, f\right)=u_{x}\left(x_{0}, f\right)-u_{x_{\text {hydro }}}\left(x_{0}, f\right) \mathrm{e}^{-i K_{c} x_{0}}
$$

The magnitude of axial velocity harmonics obtained after filtering the hydrodynamic modes is plotted in Fig. 13. It has to be compared with the raw CFD data shown in Fig. 6 (on bottom) and used to perform the first PWL predictions with the $\mathrm{C} \& \mathrm{H}$ formulation (shown in Fig. 10). Thus it is clearly shown that almost all spots which were revealed beyond each vane location for the axial velocity disturbances have been almost deleted thanks to the filtering process. Moreover the amplitudes of the filtered axial velocity harmonics are now in accordance with the acoustics order of magnitude.

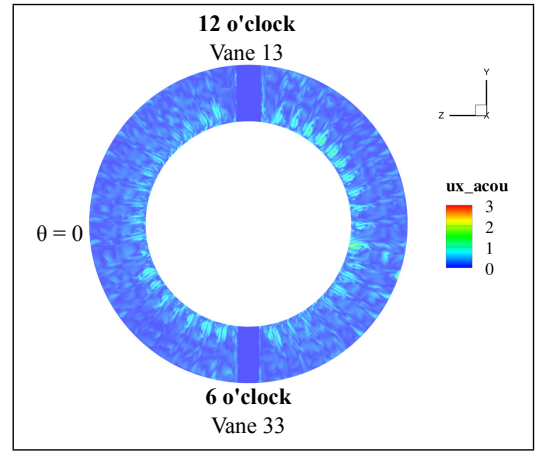

(a) Magnitude $(\mathrm{m} / \mathrm{s})$ of axial velocity harmonic - 1BPF

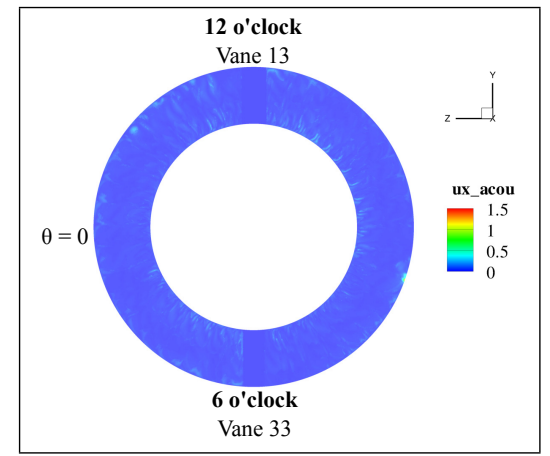

(b) Magnitude $(\mathrm{m} / \mathrm{s})$ of axial velocity harmonic - 2BPF

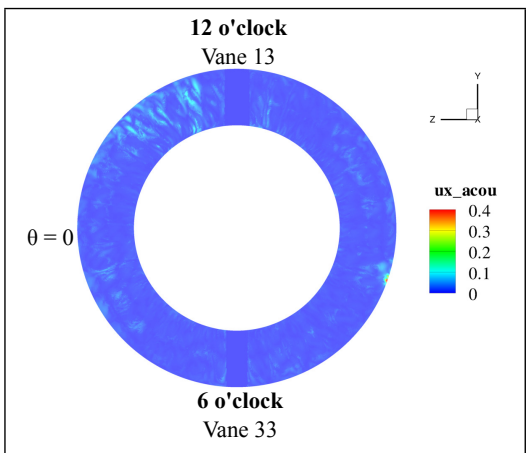

(c) Magnitude $(\mathrm{m} / \mathrm{s})$ of axial velocity harmonic - 3BPF

Figure 13. Axial velocity field in the microphone cross-section after filtering 


\section{V.D. Calculation and control of the conservation of the sound power in the bypass duct}

Finally, the sound power spectra in Fig. 10 have been updated with the new C\&H predictions performed with the filtered axial velocity. In order to control the accuracy and the robustness of the models, sensitivity of the predictions against the axial position of the extraction planes has been checked to verify the conservation of sound power. The conservation of the sound power spectra (from 1BPF to 3BPF) predicted from the modal expansion of the unsteady pressure field is perfectly highlighted in Fig. 14(a). Indeed, the power levels are practically constant over the extraction planes. In the same way, the sound power spectra predicted by the $\mathrm{C} \& \mathrm{H}$ formulation over all the extraction planes with and without filtering is plotted in Fig. 14(b). First, the sound power predictions provided by the raw CFD (dashed lines) shows a fairly good conservation for extraction planes located close to the stator. The light drop of the sound power level (PWL) farther from the stator might be due to of the attenuation of the hydrodynamic disturbances convected with the flow and responsible in the over-prediction of the PWL in the stator area. When filtering these hydrodynamic modes (solid lines) the sound power level of each tone clearly decreases, particularly for 1BPF. A noticeable conservation of the sound power is found for axial positions centered around $-140 \mathrm{~mm}$, i.e. around the middistance from the upstream to the downstream boundaries of the analysis area. Close to these boundaries, the level is rising because of the truncation effects of the filtering process. Indeed, in theory, the integral of Eq. (18) is centered around the axial position $x_{0}$ of each extraction plane, but for extraction planes close to the boudaries, it is needed to decenter "on the right" (for extraction planes in upstream side) or "on the left" (for extraction planes in downstream side). A larger analysis window (requiring a more extended domain for the CFD computation, and so a CPU most costly) would allow to reach a longer plateau.

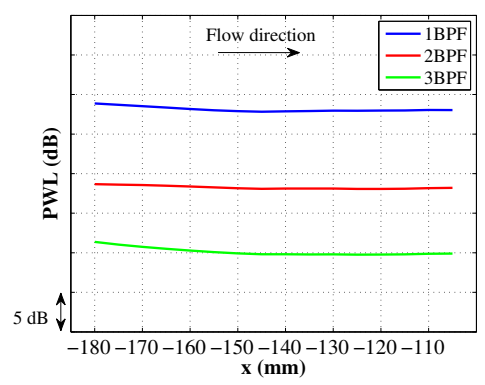

(a) Modal expansion model

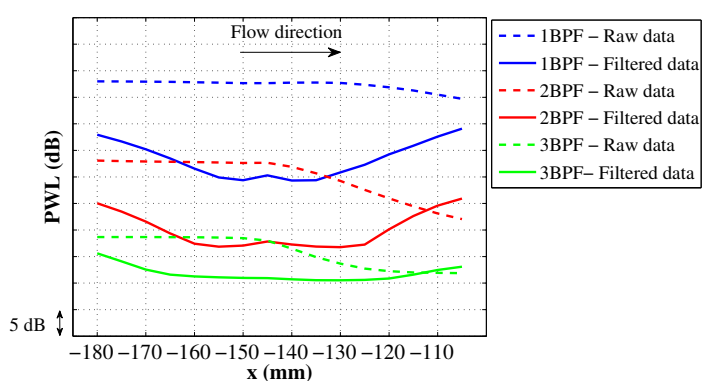

(b) $\mathrm{C} \& \mathrm{H}$ model with and without filtering

Figure 14. Control of the sound power conservation over the extraction planes

Further analyses have been led in order to control the effect of the convection velocity, $U_{c}$, used for the hydrodynamic modes filtering. Figure 15 shows the sound power spectra predicted by the $\mathrm{C} \& \mathrm{H}$ formulation using the convection velocity given by Eq. (17) (in red) or setting the convection velocity equal to the mean axial velocity (in blue), or equal to $90 \%$ of the mean axial velocity (in green). It is noticed a quite negligible impact on the sound power levels.

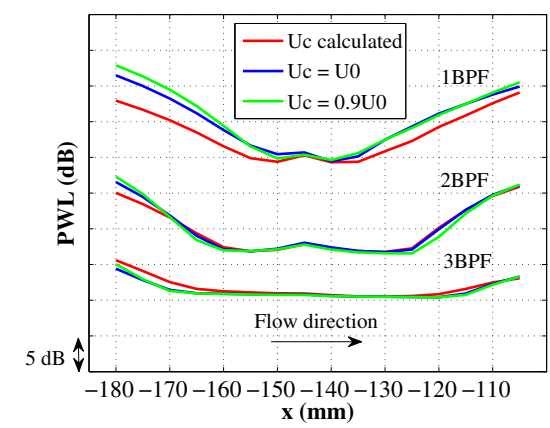

Figure 15. Effect of the choice of the convection velocity on the filtering result for the sound power prediction by $\mathrm{C} \& \mathrm{H}$ formulation over the extraction planes

Finally the sound power spectra predicted using the three formulations are again compared in Fig. 16 regarding the $\mathrm{C} \& \mathrm{H}$ solution obtained for the extraction plane located at the axial position -140 mm (cor- 
responding to the optimal value of the plateau in Fig. 14(b)). The three methods lead to a fairly good agreement now on the first two tones, while a gap (around 6-7dB) between the FWH solution and the direct methods is noticed on $3 \mathrm{BPF}$. This gap may be partly due to $3 \mathrm{D}$ scattering effects that tend to invalidate the flat plate assumption when the acoustic wavelength is comparable to the thickness of the bifurcation, although the FWH and the modal expansion solutions are using the same assumption. Numerical dissipation effects should be low since the CFD grid was designed to ensure more than 30 points per wavelength on $3 \mathrm{BPF}$ in the bypass duct. Another possible explanation can be attributed to actual convection effects that are not taken into account in the FWH formulation (considering a uniform flow between sources and observers). In particular, it is possible that these convection effects were more significant for heterogeneous stators (as compared with homogeneous stators) because of the high number of propagative modes (which increases with the frequency) contributing to the sound energy generated by the sources of interaction noise (see Fig. 11) whereas only a few interaction modes are involved in conventional rotor-stator mechanisms.

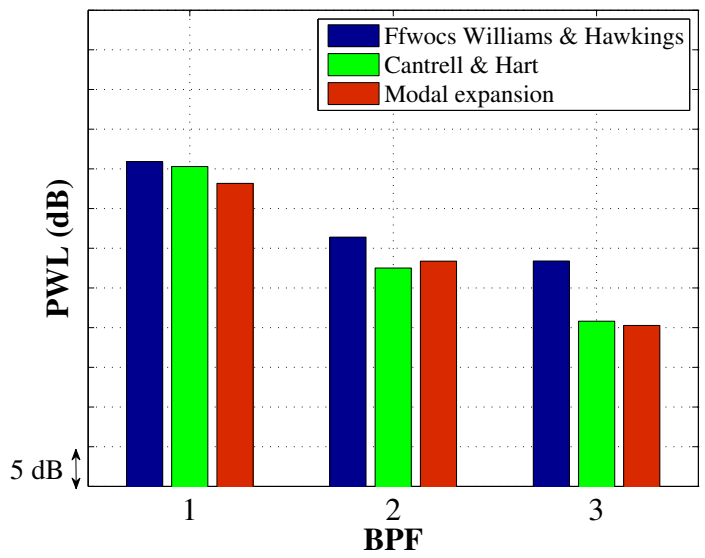

Figure 16. PWL (dB) spectra predicted from FWH (blue) and both direct calculation methods: C\&H (green) and modal expansion (red) after filtering the hydrodynamic modes

\section{Validation of CFD data and acoustic predictions with the measurements}

This last section shows the comparisons between the computations and the available measurements in order to control the reliability of the CFD data and the acoustic models.

\section{VI.A. Comparison of harmonic pressure disturbances on the stator vanes with the measure- ments from Kulite sensors}

The measurements with Kulite sensors were undergone on four reference stator vanes as shown in Fig. 17(a). These two couples of vanes have the same geometry and have been selected in order to acquire measurements at two azimuthal positions. By this way, for both azimuthal positions, the adjacent vanes allow describing a complete profile with simultaneous measurements on the pressure side of one vane and on the suction side of the other vane, as illustrated in Fig. 17(b). A total of 20 Kulite sensors have been used to scan the reference vane surface: 7 sensors on the suction sides, 9 sensors on the pressure side, distributed at half-span as shown in Fig. 17(c), and 5 sensors over the leading edge which have been lightly moved over the suction side for operability reasons, as shown in Fig. 17(d). The comparisons displayed here are relative to the first azimuthal position (Pos. 1, vanes 29 and 30) for axial and radial positions describe in Fig. 17(c) and Fig. 17(d). 


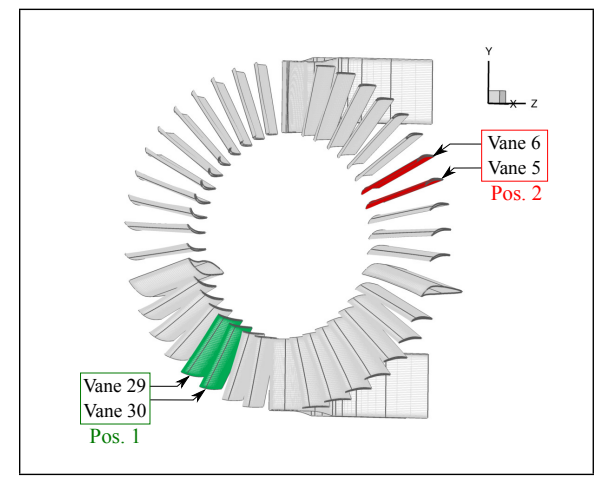

(a) Identification of instrumented vanes (upstream stator view)

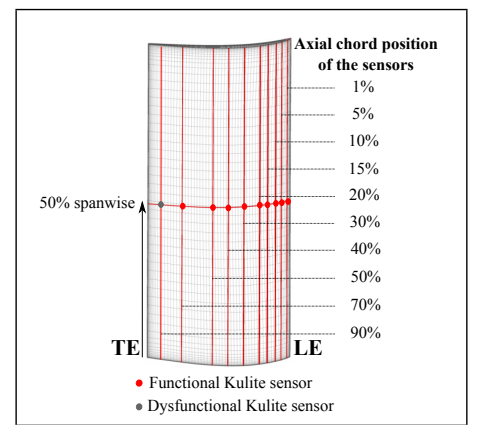

(c) Axial positions of the sensors on the suction side

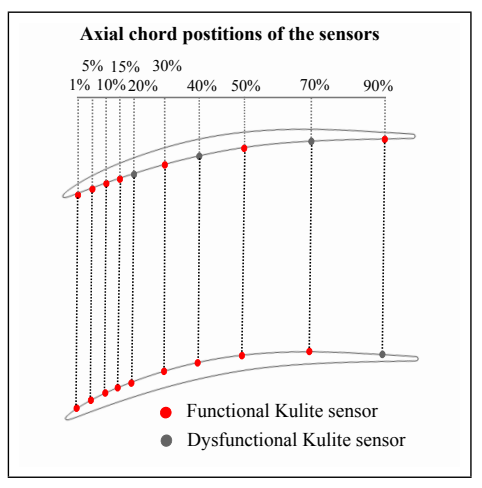

(b) Distribution of the Kulite sensors on the pressure and suction sides of the adjacent vanes

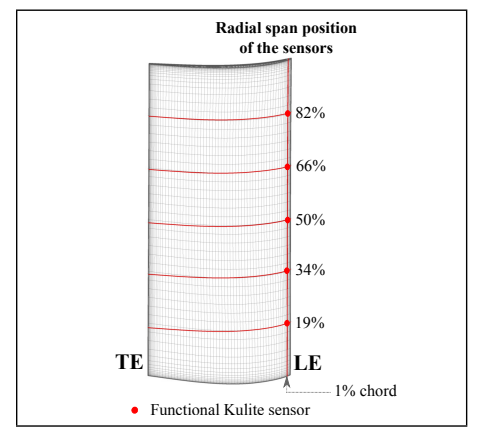

(d) Radial positions of the sensors on the leading edge

Figure 17. Localization of the Kulite sensors over the stator vanes

Figure 18 shows the distribution around the profile of the pressure harmonics at half-span from the URANS chorochronic computation (Snecma calculation), the $360^{\circ}$ computation (Onera calculation), and the measurements. A fairly good agreement is noticed on the fundamental tone whereas a few differences appear on $2 \mathrm{BPF}$ and $3 \mathrm{BPF}$. Although the chorochronic calculation assumes identical stator vanes (same vanes as those selected for the measurements) the related predictions seem to be closer to the measurements for these two tones, in particular for 2BPF. However, the large SPL dynamic of at least $25 \mathrm{~dB}$ must be underlined between the maximum close to the leading edge and the other part of the profile beyond $10 \%$ of chord. Hence, the overall level is dominated by the leading edge peak. These pressure peaks agree with the measurements, although the lack of sensor over the stagnation point does not permit to capture the peak magnitude provided by the CFD. Moreover, possible errors in the measurements linked to the limited dynamic range of the sensors are not excluded.

The radial profiles from the URANS chorochronic computation and the $360^{\circ}$ computation are compared in Fig. 19 with the sensors located on the leading edge. High level fluctuations versus the span position are noticeable on the numerical solutions but also on the measurements. That is why it is difficult to conclude about the accuracy benefit of the $360^{\circ}$ calculation compared to the chorochronic solution. However, the overall levels fluctuate around a mean value close to experimental data. 


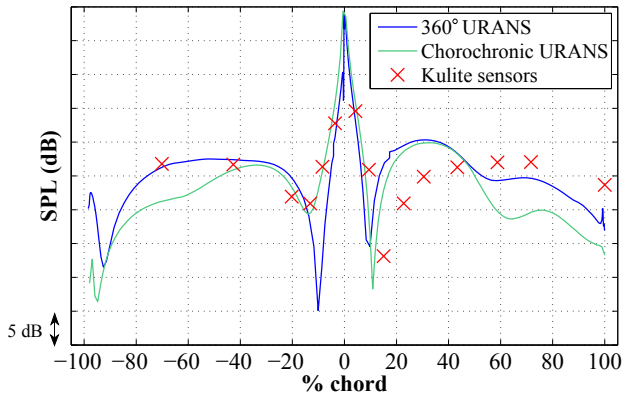

(a) $1 \mathrm{BPF}$

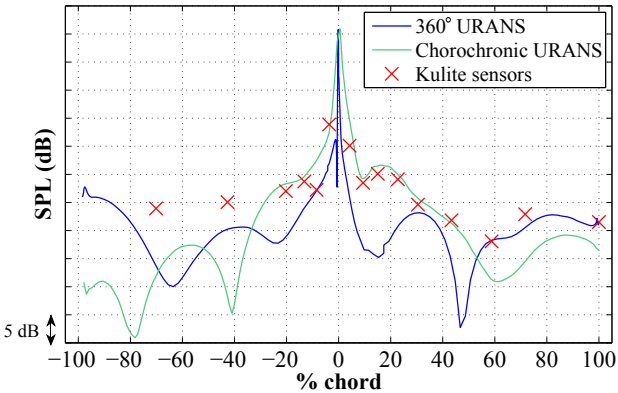

(b) $2 \mathrm{BPF}$

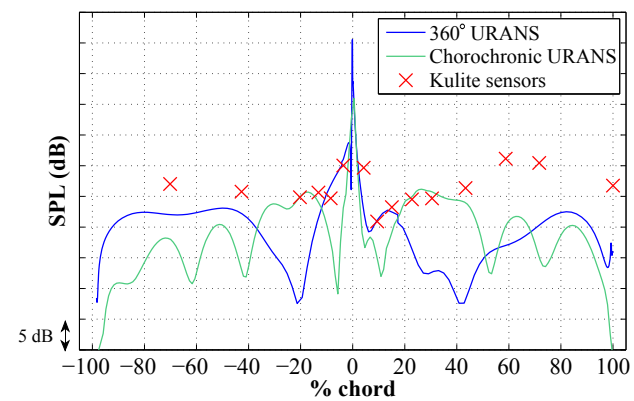

(c) $3 \mathrm{BPF}$

Figure 18. Comparisons of the pressure harmonics (dB) along the profile at half-span: the chorochronic RANS calculation (green), the $360^{\circ}$ RANS calculation (blue) and the measurements provided by the Kulite sensors (red crosses)

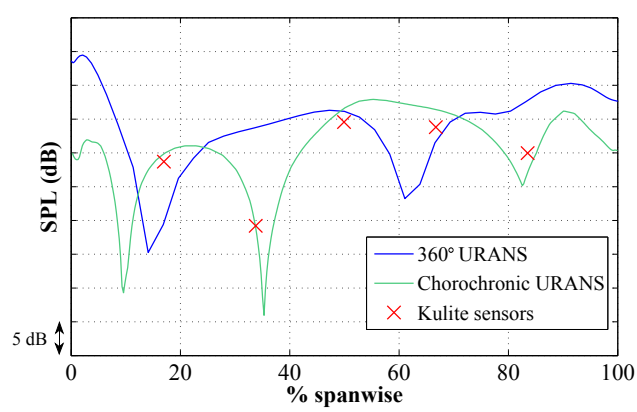

(a) $1 \mathrm{BPF}$

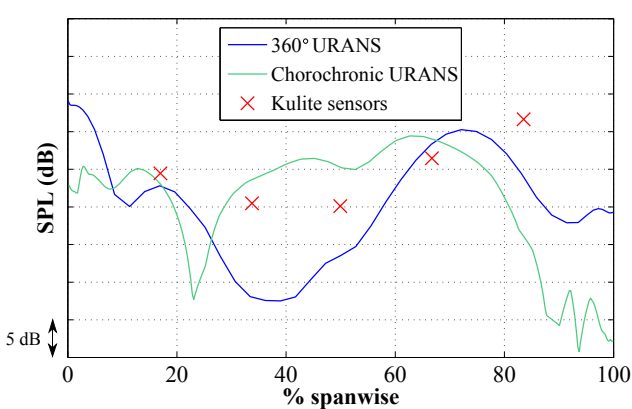

(b) $2 \mathrm{BPF}$

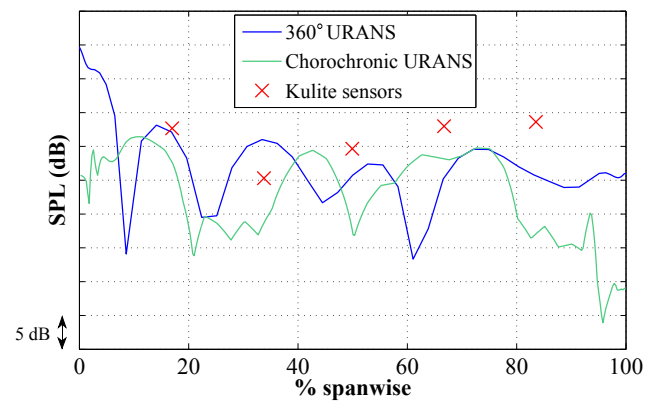

(c) $3 \mathrm{BPF}$

Figure 19. Comparisons of the pressure harmonics (dB) near the leading edge along the span: the chorochronic RANS calculation (green), the $360^{\circ}$ RANS calculation (blue) and the measurements provided by the Kulite sensors (red crosses) 


\section{VI.B. Comparison of SPL predictions with the measurements from two wall mounted micro- phones}

As illustrated in Fig. 20, two microphones are flush-mounted on the wall of a cross-section downstream of the stator and located at $261^{\circ}$ and $351^{\circ}$. Figure 21 shows the sound pressure level on the outer wall from the direct CFD calculation, the modal reconstruction (see Fig. 9) and the in-duct acoustic measurements. A fairly good agreement is noticed between the raw CFD and the modal reconstruction which confirms the reliability of the modal expansion with the flat plate assumption (seen in Section V.B). The strong fluctuations (more than $30 \mathrm{~dB}$ ) of the sound pressure level from the raw CFD and the modal reconstruction are due to the standing waves that give rise to cancellation patterns. For this reason, it is almost impossible to validate the predictions using only two microphones. However, a reasonable agreement is found with the mean azimuthal SPL (black dotted line) between the computation and the measurements.

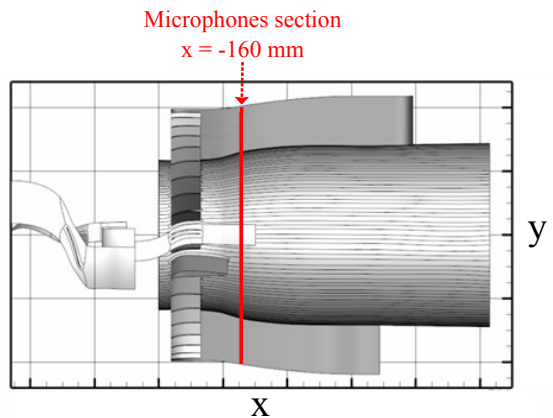

(a) Axial position of the microphones (fan-OGV side view)

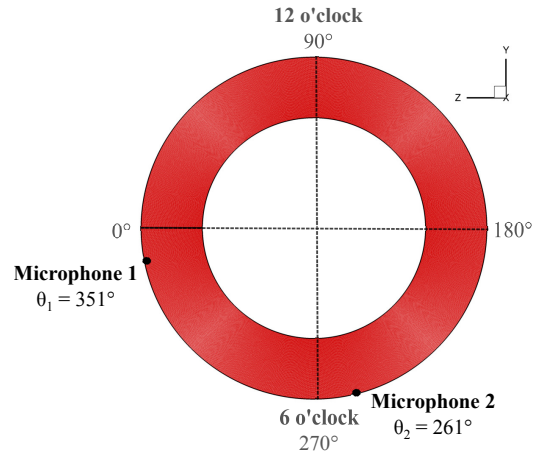

(b) Angular position of the microphones (stator rear view)

Figure 20. Location of the microphones in the bypass duct, downstream of the stator

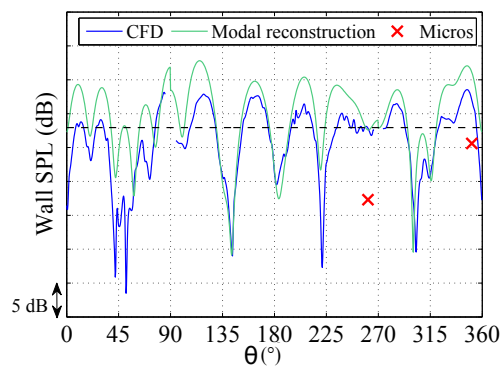

(a) $1 \mathrm{BPF}$

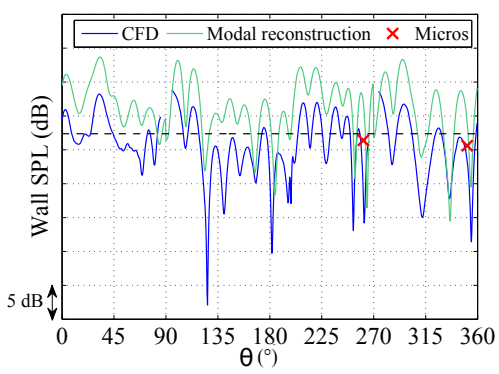

(b) $2 \mathrm{BPF}$

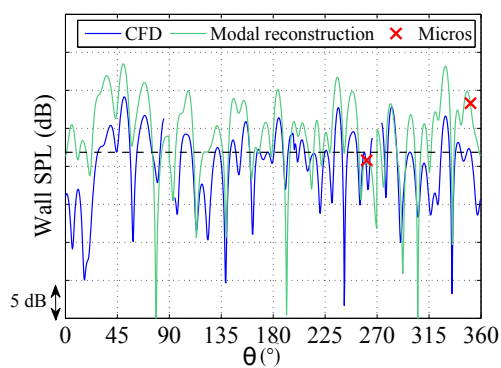

(c) $3 \mathrm{BPF}$

Figure 21. Comparisons of SPL $(\mathrm{dB})$ on the outer wall: CFD (blue), modal reconstruction (green) and two microphones measurements (red crosses)

\section{VI.C. Comparison of the sound power predictions with the far field measurements}

Finally, the in-duct sound power level (PWL) predictions downstream of the OGV are compared to the sound power estimations using the downstream measurements provided by the external microphone array (Fig. 2(b)), assuming that the transmission coefficient is equal to 1 . The path of the microphone array is detailed in Fig. 22, the focus being set here on the downstream arch. Despite the axisymmetric directivity assumption and the uncertainties due to the scanned angles of the measurements limited to the arch $\left[90^{\circ}\right.$ $140^{\circ}$ ] $\left(180^{\circ}\right.$ corresponding to the duct rear centerline), the agreement between the computation and the experimental data compared in Fig. 23 is very satisfactory. In particular, the measured sound power levels at $2 \mathrm{BPF}$ and $3 \mathrm{BPF}$ are close to the mean power level estimated from the three solutions. The gap observed for the fundamental tone (about $10 \mathrm{~dB}$ ) might be partly due to the reflections beyond the exhaust of the bypass duct. These reflections might be more significant in low frequencies for which the radiated power is probably lower than the induct power (transmission coefficient lower than 1). 


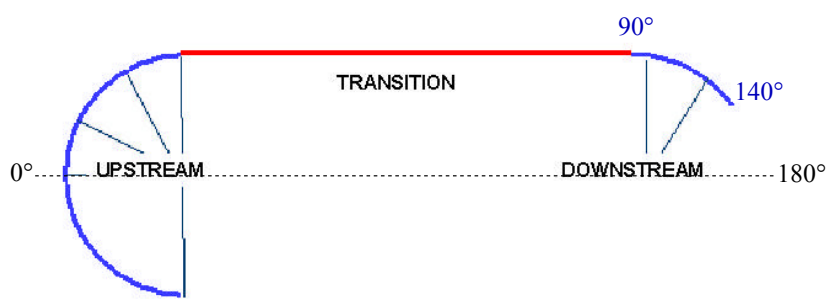

Figure 22. Path described by the microphone array

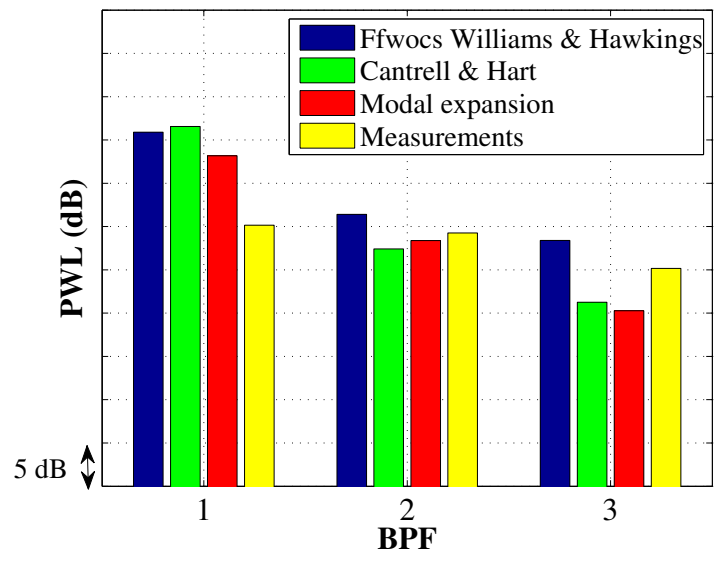

Figure 23. Comparisons of the sound power spectra (dB) predictions: FWH formulation (blue), C\&H formulation with filtered data (green), modal expansion (red), far field measurements (yellow)

\section{Conclusion}

Analytical and numerical calculations aiming at estimating the sound power spectrum due to rotor-stator interaction in the case of a realistic aeroengine configuration were investigated in this study. Turbofan model from Snecma features non identical vanes, integrated struts and bifurcations which were modeled thanks to a $360^{\circ}$ URANS computation using fine multi-block grids well adapted for wake capture and sound propagation in the bypass duct. This computation was chained to the FWH analogy and to direct calculation of the sound power, both detailed in the paper. The formulations were developed to take into account both the heterogeneity of the OGV and the presence of the bifurcations in the bypass duct.

It was showed that the rupture of azimuthal symmetry of the stator gives rise to additional interaction modes (all propagating duct modes have to be considered) so that the BPF usually cut-off on standard homogeneous OGV is now cut-on and mainly responsible for the overall sound power level. A theoretical analysis was also addressed in order to simulate the acoustic propagation in the bypass duct in the presence of 6 o'clock and 12 o'clock pylons (denoted as C-duct) modeled here by flat plates, and responsible for the blockage of the spinning modes and of standing waves in the angular direction. This effect was clearly visualized from the pressure disturbances provided by the URANS calculation, highlighting a stationary acoustic field along axial cross-sections beyond the stator vanes (and crossing the bifurcations).

A first attempt to relate the sound power spectrum predictions deduced by coupling the CFD to a FWH formulation (loading sources on stator vanes) to the spectrum directly assessed by integrating the acoustic intensity over a prescribed axial cross section was suggested. The direct calculation of intensity using Cantrell and Hart expression is polluted by the presence of hydrodynamic modes due to pulsating flow separations in the stator hub region and largely contributing to the level on the BPF. A filtering process of the hydrodynamic contribution was successfully carried out on the axial velocity field.

On the other hand, a modal expansion of the pressure disturbances along the cross section (not contaminated by the velocity-based hydrodynamic modes) was suggested thanks to the flat plate assumption. The sound power predictions from the Cantrell and Hart formulation and the modal expansion showed a reasonable agreement with the FWH solution.

The comparisons with the available measurements allowed to partly validate the developed acoustical 
models. The measurements from Kulite sensors over a couple of reference vanes showed a satisfactory agreement. In particular the pressure harmonics issued from the computation displayed a overall level highly dominated by the leading edge peak in good agreement with the measurements. Finally, the sound power spectrum calculated downstream of the stator was compared with the radiated power estimated from the external microphone array measurements. A fairly good agreement was obtained for $2 \mathrm{BPF}$ and $3 \mathrm{BPF}$. The over-estimation calculated for the fundamental tone might be attributed in part to a sound transmission beyond the exhaust lower on low frequencies leading to a level loss between the induct power and the radiated power.

\section{Acknowledgments}

The authors thank the French aeroengine manufacturer Snecma (Safran group) for having funded this study.

\section{References}

\footnotetext{
${ }^{1}$ Gerolymos G.-A., Michon G.-J., Neubauer J, Analysis and application of chorochronic periodicity in turbomachinery rotor-stator Interaction computations, in Journal of propulsion and power, Vol. 18, No. 6, - pp. 1139-1152, 2001

${ }^{2}$ Goldstein M.-E., Aeroacoustics, McGraw-Hill, New-York (US), 1976

${ }^{3}$ Bauers R., Tapken U., Enghardt L., Stöhr C., Experimental study of acoustic mode transmission through C-shaped bypassduct sections of aero-engines, ICSV16 conference, Krakóv (Poland), 2009

${ }^{4}$ Polacsek C., Barrier R., Bonneau V., Prediction of harmonic sound power generated by a modern turbofan with heterogeneous $O G V$ and internal bifurcations, Inter-Noise conference, Innsbruck (Austria), 2013

${ }^{5}$ Genoulaz N., Julliard J., Lozachmeur C., Caujolle C., RACE aeroacoustic test facility: fan forward and rearward $3 D$ noise measurements, AIAA paper 2006-2551, 2006

${ }^{6}$ Cambier L., Heib S., Plot S., The Onera elsA CFD software: input from research and feedback from industry, Mechanics \& Industry, Vol. 14, No. 3, 2013, pp. 159-174

${ }^{7}$ Tyler M., Sofrin T.-G., Axial flow compressor noise studies, Society of automotive engineers transactions, Vol. 70, pp. 309-332, 1962

${ }^{8}$ Druon Y., Etude de la propagation guidée et du rayonnement acoustique par les conduits d'éjection de turboréacteur, Mémoire de thèse de doctorat (ECL), 2006

${ }^{9}$ Redonnet S., Druon Y., Computational aeroacoustics of aft fan noises characterizing a realistic coaxial engine, AIAA journal, Vol. 50, No. 5, May 2012

${ }^{10}$ Cantrell R.-H., Hart R.-W., Interaction between sound and flow in acoustic cavities: mass, momentum, and energy considerations, Journal of the acoustical society of America, Vol. 36, No. 4, pp. 697-706, 1964

${ }^{11}$ Polacsek C., Barrier R., Lewy S., Computation of acoustic power generated by aeroengines in subsonic and transonic conditions, CIAM conference on aeroengine of XXIst Century, Moscow, Russia, 2010

${ }^{12}$ Polacsek C., Burguburu S., Redonnet S., Terracol M., Numerical simulation if fan interaction noise using a hybrid approach, AIAA Journal, Vol. 44, No. 6, pp. 1188-1196, 2006
} 



\section{ONERA}

BP 72 - 29 avenue de la Division Leclerc - 92322 CHATILLON CEDEX - Tél. : +33 146734040 - Fax : +33 146734141

w w w. onera.f r 